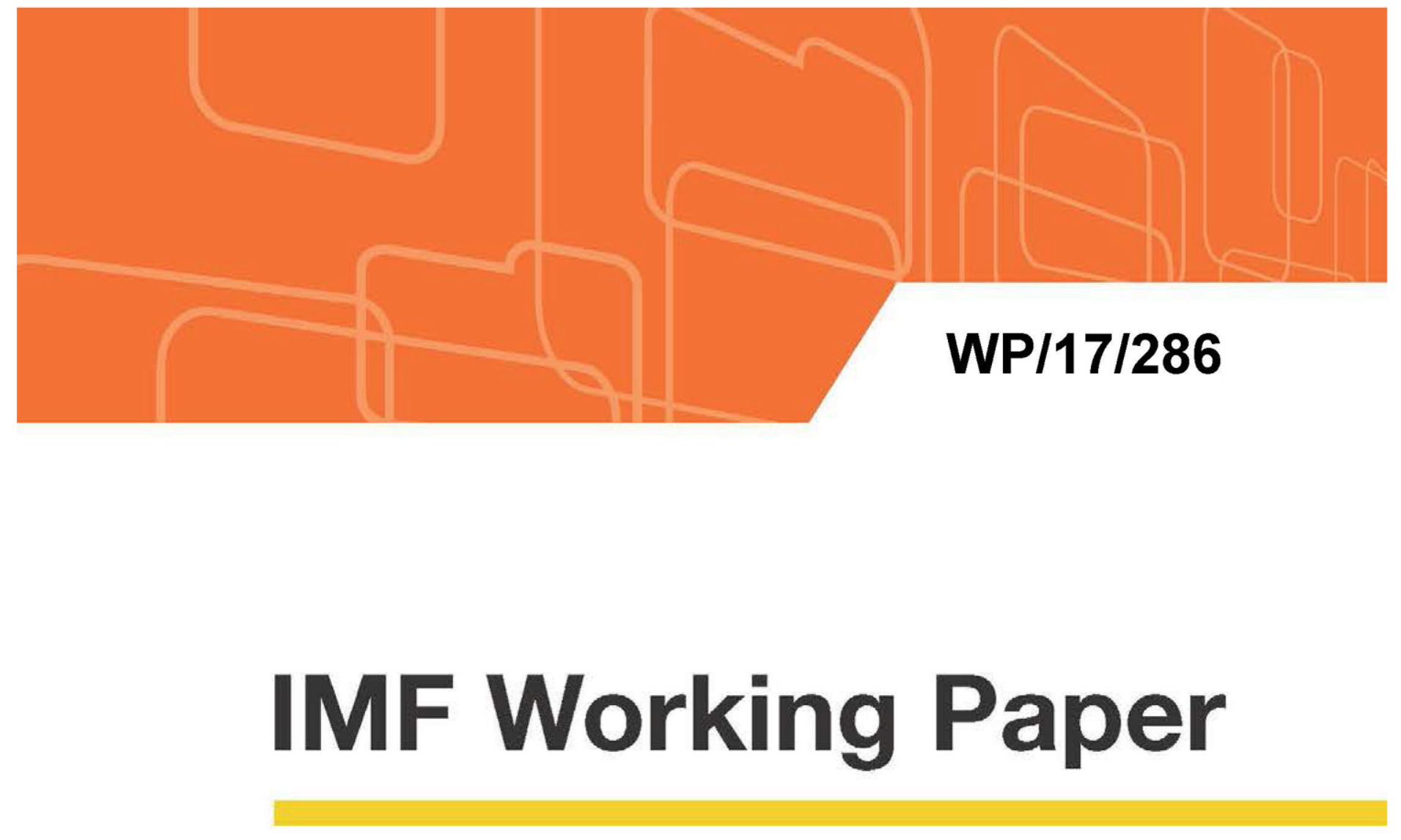

\title{
Australia's Fiscal Framework: Revisiting Options for a
}

Fiscal Anchor

by Allan Dizioli, Philippe Karam, Dirk Muir, and Siegfried Steinlein

IMF Working Papers describe research in progress by the author(s) and are published to elicit comments and to encourage debate. The views expressed in IMF Working Papers are those of the author(s) and do not necessarily represent the views of the IMF, its Executive Board, or IMF management. 


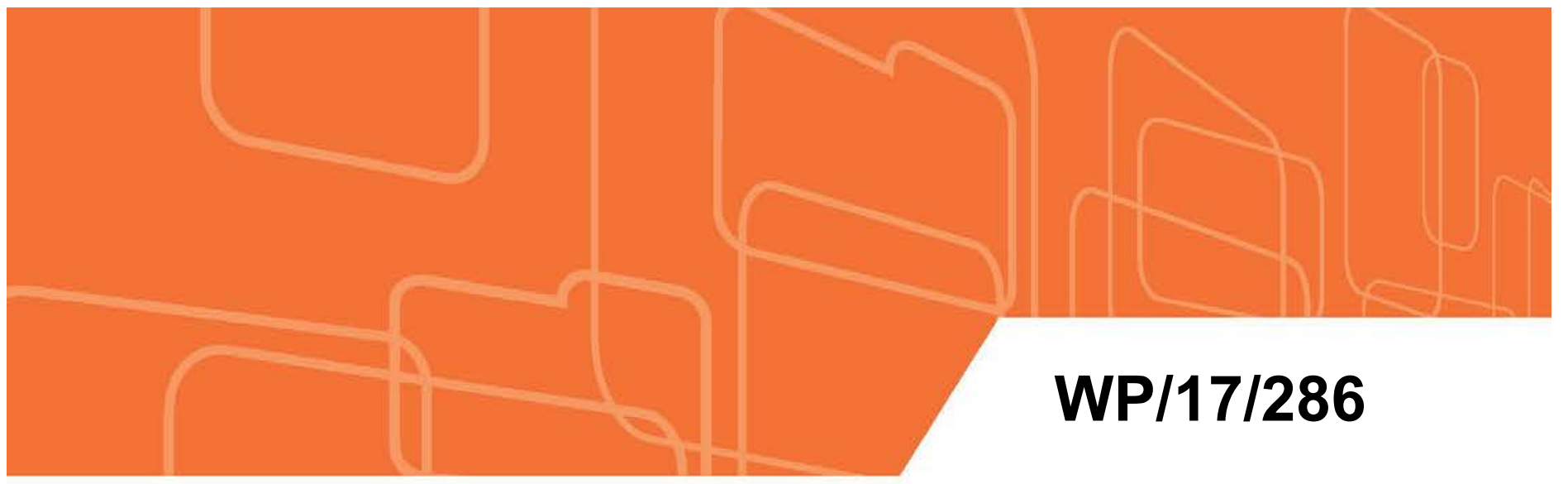

\section{IMF Working Paper}

\section{Australia's Fiscal Framework: Revisiting Options for a} Fiscal Anchor

by Allan Dizioli, Philippe Karam, Dirk Muir, and Siegfried Steinlein

IMF Working Papers describe research in progress by the author(s) and are published to elicit comments and to encourage debate. The views expressed in IMF Working Papers are those of the author(s) and do not necessarily represent the views of the IMF, its Executive Board, or IMF management.

$$
\text { I N T E R N A T I O N A L M O N E T A R Y F U N D }
$$




\title{
IMF Working Paper
}

Asia and Pacific Department and Research Department

\author{
Australia's Fiscal Framework: Revisiting Options for a Fiscal Anchor \\ Prepared by Allan Dizioli, Philippe Karam, Dirk Muir, and Siegfried Steinlein ${ }^{1}$
}

Authorized for distribution by Thomas Helbling

December 2017

IMF Working Papers describe research in progress by the author(s) and are published to elicit comments and to encourage debate. The views expressed in IMF Working Papers are those of the author(s) and do not necessarily represent the views of the IMF, its Executive Board, or IMF management.

\begin{abstract}
This paper revisits options for fiscal anchors in Australia against the backdrop of a medium-term budget balance anchor that has led to larger than expected upward drift in the net debt to GDP ratio since the end of the mining investment boom. The IMF's G20MOD model is used to compare the budget balance anchor with a long-term debt anchor. Using model simulations evaluated against objective macro stabilization-debt control criteria under three likely scenarios for the Australian economy, the latter is found to perform at least as well as the former. The paper also considers the operationalization of a long-term debt anchor utilizing a combination of fiscal rules which includes expenditure restrictions and a flexible time horizon for convergence, aiming at encouraging countercyclical fiscal policy and minimizing the cost in terms of real GDP foregone in the medium term under fiscal consolidation.
\end{abstract}

JEL Classification Numbers: E12; E17; E61; E62; H20; H30; H54; H63

Keywords: Fiscal policy; fiscal rules; general equilibrium models; taxation; debt Authors’ E-Mail Addresses: adizioli@imf.org; pkaram@imf.org; dmuir@imf.org; ssteinlein@imf.org

\footnotetext{
${ }^{1}$ The authors would like to thank Thomas Helbling, Benjamin Hunt, staff at the Australian Treasury, and participants at an Australian Treasury seminar in Canberra, Australia in November, 2016 for useful comments on an earlier draft.
} 
Table of Contents

I. INTRODUCTION

II. UNDERSTANDING THE MODEL___ $\underline{\mathbf{5}}$

A. Brief Overview of the Theoretical Structure __ $\underline{5}$

B. Fiscal Policy __ $\underline{6}$

C. Fiscal Rules__ $\underline{6}$

D. Calibrating the Australian Economy ___ $\underline{7}$

The External Sector and Commodities___ $\underline{8}$

The Domestic Economy ___ $\underline{9}$

Fiscal Rules __ $\underline{9}$

III. THE MEDIUM-TERM FISCAL STRATEGY _ _ 10

A. Performance Before the Global Financial Crisis __ 11

B. Performance Since the Budget Repair Strategy ___ 12

C. Performance Under the Budget Repair Strategy Going Forward ___ 14

IV. THE INTERGENERATIONAL REPORT AND LONG-TERM PRESSURES _ $\underline{15}$

V. A MODEL-BASED ANALYSIS OF FISCAL ANCHORS __ 19

A. The Argument for a Long-Term Debt Anchor ___ 20

B. Implementing the Long-Term Debt Anchor with Fiscal Rules ___ 27

C. Evaluating the Aggregated Fiscal Rules Under Illustrative Scenarios ___ $\underline{31}$

VI. CONCLUSIONS __ $\underline{33}$

References ___ $\underline{33}$

Appendix I: Overview of the Theoretical Structure of G20MOD__ 


\section{INTRODUCTION}

This paper revisits options for fiscal anchors, which guide the conduct of fiscal policy in Australia by the Commonwealth government (or, the 'Government') in the medium to long term. Currently, the Government is pursuing a 1 percent of GDP budget surplus (the 'mediumterm budget balance anchor'), which guides its medium-term fiscal strategy. This anchor and the related medium-term strategy have led to drift in the net public debt ratio, which has led to concerns in Australia where low and stable public debt ratios are widely seen as a virtue. For reasons outlined in the following sections, this paper analyses a scenario with a shift in the Government's conduct of fiscal policy using the IMF's model, G20MOD, to a fiscal rule anchored by debt, with the intention of further enhancing the performance of the Government under its medium-term fiscal strategy, against macro stabilization and debt control.

A fiscal policy framework should provide for institutions and methods to conduct fiscal policy over time in a consistent manner so that the fiscal authority, in this case the Government, can maximize the use of its resources to foster strong and stable economic performance. ${ }^{2}$ This includes ensuring debt is sustainable, and that the economy does not face undue burdens from its spending and taxation choices, which should be made in a manner consistent with a society's choices. A sound fiscal framework is key to a sound fiscal position, by fostering fiscal responsibility, which, over time, underpins policy credibility.

Australia's fiscal policy framework is laid out in the Charter of Budgetary Honesty Act 1998 (Commonwealth of Australia, 2014a). The framework provides for "constrained discretion," advocating a principles-based approach rather than a numerically-oriented, rules-based fiscal framework. The Charter lays out procedures for setting fiscal objectives based on its "Principles of Sound Fiscal Management," which are stated in general terms. The fiscal objectives comprise the medium-term fiscal strategy, which is spelled out in a "Fiscal Strategy Statement" as part of the annual budget documents. There is extensive reporting required to transparently present the fiscal outlook, including the budget itself, a Mid-Year Economic and Fiscal Outlook, and a final budget outcome report. There is also reporting related to the fiscal situation when an election is called, and to cost proposed measures for party platforms during elections. Finally, there is the Intergenerational Report to be released every five years, which is an assessment of the longterm sustainability of policies that are current at the time of the report's release 40 years into the future, with an explicit consideration of demographic issues.

Since the inception of the Charter in 1998, elements of the medium-term fiscal strategy have been closely pursued and applied within Australia's fiscal framework. Budget balance policies have been at the center of all successive Governments' fiscal strategy statements since 1996. Additional policies have varied over time. Policies related to levels of (net) debt, levels of net (financial) worth, caps on the tax share in GDP, or a cap on expenditures, among others, have been included. Different auxiliary strategies, such as that of budget repair, currently based on the

\footnotetext{
${ }^{2}$ For a more thorough discussion of fiscal frameworks, see, for example, Baunsgaard and others (2012).
} 
medium-term balance anchor, have been deployed to achieve the high policy objectives. In this vein, this paper examines the possibility of the Government employing a different basis for achieving its medium-term fiscal strategy - a long-term debt anchor.

The paper is organized as follows. Section II introduces the analytical tool used here. Section III discusses the Government's medium-term fiscal strategy and anchor, and evaluates them in the broader context of Australia's fiscal framework. Section IV considers longer-term issues related to demographics found in the Intergenerational Report. Section V compares alternative fiscal anchors using model simulations. Concluding comments are in Section VI.

\section{Understanding THE Model}

The analysis below is based on the G20MOD module of the IMF's Flexible System of Global Models (FSGM). This section discusses the features most salient to our fiscal analysis for Australia. An extensive discussion of the fiscal rules framework being used follows, and a closer calibration of the model for Australia is geared at highlighting the important macroeconomic interactions under the scenarios of interest.

\section{A. Brief Overview of the Theoretical Structure ${ }^{3}$}

G20MOD is an annual, multi-region, general equilibrium model of the global economy combining both micro-founded and reduced-form formulations of various economic sectors. Structurally, each country/regional block is close to identical, but with potentially different key steady-state ratios and behavioral parameters. Real GDP in the model is determined by the sum of its aggregate demand components in the short term, and the level of potential output in the long term. Aggregate demand follows the standard national expenditure accounts identity. Components such as household consumption and private investment are based on optimizing behavior, while trade is of a more semi-structural nature, and government is mostly exogenously specified. The two key prices in the model are the consumer price index (CPI) and wages, modeled by inflation and wage inflation Phillips' curves, respectively. The commodities sector consisting of oil, metals and food is modeled on both a global and country basis, with metals playing an important role in Australia. The fiscal sector is also comprehensive, and while the financial sector is simple, it provides a role in the model for both a 1-year interest rate, which serves as the short-term instrument for monetary policy, and a 10-year interest rate. The external sector is based on aggregate trade of countries with the rest of the world, instead of tracking individual bilateral relationships.

On the demand side, the key feature is a consumption block based on the Blanchard-Weil-Yaari overlapping generations (OLG) model (Blanchard 1985, Weil 1989 and Yaari 1965). Using OLG households rather than infinitely-lived households results in important non-Ricardian properties whereby the path for government debt has significant economic implications. In the

\footnotetext{
${ }^{3}$ See Appendix I for a succinct description of G20MOD. A complete description can be found in Andrle and others (2015).
} 
OLG framework, households treat government bonds as wealth since there is a chance that the associated tax liabilities will fall due beyond their expected lifetimes. The OLG formulation results in the endogenous determination of national saving and the demand for net foreign assets given the level of government debt. The global real interest rate adjusts in the long term to equilibrate the global supply of, and demand for, savings, while real exchange equilibrates a country's own supply and demand for savings relative to the global position. The central role for government debt allows for a powerful role for fiscal policy in both the short and long term. There are also households who only consume out of current income and are considered liquidity-constrained (LIQ) households.

\section{B. Fiscal Policy}

Fiscal policy is driven by a sufficiently detailed government sector that can reproduce simplified fiscal accounts for each country. Eight policy instruments are featured. On the spending side, this includes government consumption and infrastructure spending, general lumpsum transfers to all households (such as pensions, aged care provisions, unemployment insurance) and lumpsum transfers targeted to LIQ households (such as welfare and certain pensions). On the revenue side, there are taxes on consumption (the goods and services tax, GST), personal income (PIT, on both wage and dividend income) and company income (CIT), as well as taxes and royalties from the mining and production of metals. For Australia, the government is an amalgam of the Commonwealth and State governments. However, many of the issues in this paper focus on the Commonwealth accounts and balances.

The budget constraint in the model is met by the choice of a long-term deficit target, relative to GDP. Specifically, the deficit is expenditures plus interest payments on the debt, less revenues. One instrument, which is general lumpsum transfers by default, is constantly adjusted to make sure that the budget constraint always holds. The long-term government debt target, relative to GDP, can be derived from the government deficit target, based on the nominal growth rate of the economy:

$$
b^{\text {tar }}=\frac{(1+\pi)(1+g)}{(1+\pi)(1+g)-1} g d e f^{\text {tar }}
$$

where $\pi$ is inflation, $g$ is the steady-state growth rate, $b^{\text {tar }}$ is the long-term debt target, and gdef ${ }^{t a r}$ is the long-term deficit target. The explicit deficit target pins down the long-term government debt, a fundamental decision variable for firms and households worldwide. The level of government debt affects the global interest rate (the price used to equilibrate global saving with global investment) and the real exchange rate (a country's relative price for its contributions to and use of the global saving-investment pool). The government meets its deficit target using a fiscal rule, as discussed in the next section.

\section{Fiscal Rules}

This version of the model is configured to use a combination of up to three primary fiscal rules, as defined in IMF (2009). 
- Expenditure rule (ER) - The Government specifies some restriction on some component of spending to provide control. The ER does not directly provide any restriction to the budget balance, as it does not imply any restriction on the revenue side of the economy, or its borrowing intentions.

- Budget balance rule (BBR) - The Government specifies some restriction to ensure the budget meets a specified target level after some time horizon. A balanced budget (where the deficit is zero) is special case of a BBR. The BBR also implies a long-term debt level (see the equation above relating the deficit and debt targets), but this is not a required consideration for the choice or implementation of its particular form.

- Debt rule (DR) - brings the government debt to some specified target level over some time horizon.

The BBR and the DR can be either strict or flexible. 'Strict' means the target level for the BBR or the target path for the DR is met in full each year and 'flexible' means the BBR's target level or the DR's target path is met on average over some time horizon - for example, "over the business cycle" or "over the course of three years."

G20MOD's deficit target is a strict BBR, but also embeds a short-term feature which provides some flexibility. The Government has an obligation to provide social transfers (such as unemployment insurance, or welfare). These are part of the general lumpsum transfers in G20MOD intended to smooth the business cycle (i.e. provide more unemployment insurance in the recessionary phase of excess supply, and less in the expansionary phase of excess demand). Therefore, under this strict BBR, the deficit-to-GDP target translates into the deficit-to-GDP ratio $g d e f^{\text {rat }}$, while allowing for flexibility:

$$
g d e f^{r a t}=g d e f^{t a r}-d^{y g a p} y^{g a p}
$$

where $d^{y g a p}$ is the countercyclical weight on the measure of the output gap, $y^{g a p}$. In referring to the automatic social transfers below, these are related to the additional spending (or saving) that is always added to general lumpsum transfers.

\section{Calibrating the Australian Economy}

This subsection describes the salient parameter values for G20MOD as used in this paper. Most of the parameters are calibrated for the model as a whole, using the process explained in Andrle and others (2015). Some of the baseline data is also key for the behavior of the Australian economy, particularly the share of the commodity sectors, and the trade relationships with the rest of the world. Calibration is informed by estimation work associated with older versions of G20MOD, stylized facts, and properties of the IMF's other structural macroeconomic models. The goal is to obtain sensible system-wide properties. Given that the calibration is for a steady state in the model, the numbers may not match raw data in quantity, but should qualitatively capture their significance. 


\section{The External Sector and Commodities}

Important factors in calibrating Australia's external sector are data related to its size (Table 1). Australia has a small share of global GDP approximately 1.6 percent. Its permanent fiscal shocks have little impact on global real interest rates (unlike the United States or euro area, for example). However, it is a large market participant in the

\begin{tabular}{|lcc|}
\hline \multicolumn{3}{|c|}{ Table 1. External Sector Calibration } \\
\hline \% Share of Global GDP for Australia & 1.57 \\
\% Share of Real GDP & Exports & Imports \\
Aggregate & 24.6 & 23.5 \\
Oil & 0.8 & 2.2 \\
Mining & 8.3 & 0.0 \\
\% share of global production & 13.6 & $\ldots$ \\
\hline Sources: IMF staff calculations and World Economic Outlook \\
\end{tabular}
G20MOD's global metals market (consisting of aluminum, copper, iron, lead, nickel, tin, uranium, and zinc), with a 13.6 percent share of global production. Resources combine for roughly 9.1 percent of Australian real GDP, and are slightly below conventional calibrations of 10 to 15 percent of GDP, since the G20MOD basket is limited in its coverage.

Australia's openness is key in determining how activity in the rest of the world (in particular, China) spill over onto it, and how Australia influences the rest of the world. Australia exports about 24.6 percent of GDP, and imports 23.5 percent of GDP, which is marginally below the G20 average of 26.6 and 26.9 percent of GDP, respectively. Compare this with the United States, a less open economy, with ratios of 17.3 and 16.2 percent of GDP, respectively. Under openness, monetary and fiscal policy actions can potentially have a larger leakage component. For example, a 1 percent increase in the nominal 1-year interest rate only decreases real GDP by 0.3 percent in Australia, versus 0.4 percent in the case of the United States. Similarly, a two-year real GDP multiplier for government consumption for Australia is 0.62 , versus 0.71 for the United States.

Special attention is paid to the metals sector. The real global metals price is governed by a global equation with both production and global demand effects proxied by output gaps. The measure for demand responsiveness is weighted by metal consumption weights, and for supply responsiveness by metal production weights. The level of the metals price and the parameters governing its price dynamics and dynamics caused by reactions to metals price movements are consistent with the April 2017 WEO metals price. In Australia, the share of metals royalties and resource taxes is calibrated to be 0.75 percent of GDP, which can potentially be a source of procyclical volatility from the fiscal revenue side. As metals demand expands or metals price increases, usually in tandem with a domestic economic expansion, royalties increase and allow further government spending for a fixed debt target. The opposite is true in a recession. But given the magnitude of royalties, this effect is second order, and is not a prime driver of the scenarios discussed below. 


\section{The Domestic Economy}

Australia's economy is calibrated using roughly current national accounts ratios and fiscal ratios, with G-20 ratios reported to provide contrast (Table 2). Several features are notable. First, Australia draws much more of its tax income from CIT as a percent of GDP relative to the rest of the G-20. Second, the net foreign liability position is large relative to other G-20 debtor countries, so U.S. interest rate shocks in G20MOD can potentially pose a greater threat to Australia than other countries. Finally, Australia has low general consolidated government debt on a net basis (only 20 percent of GDP) relative to the rest of the G-20, so shocks do not have as strong effects in Australia on
Table 2. General G20MOD Calibration

\begin{tabular}{lcc}
\hline & Australia & Average G-20 \\
\hline National Accounts (\% of real GDP) & & \\
Household Consumption & 56.4 & 58.9 \\
Private Investment & 22.6 & 20.7 \\
Government Absorption & 19.9 & 20.1 \\
Exports & 24.6 & 26.9 \\
Imports & 23.5 & 26.6 \\
Public Sector (\% of GDP) & & \\
Government Debt (net) & 20.0 & 75.9 \\
Government Spending & 35.6 & 41.8 \\
$\quad$ Consumption & 16.8 & 16.0 \\
$\quad$ Investment & 4.2 & 4.9 \\
$\quad$ Transfers & 13.4 & 17.4 \\
Tax Revenues & 34.6 & 38.9 \\
$\quad$ VAT & 5.7 & 7.9 \\
$\quad$ CIT & 6.7 & 3.1 \\
$\quad$ PIT & 16.1 & 13.8 \\
$\quad$ Mining Royalties and Taxes & 0.8 & 0.0 \\
Net Foreign Liabilities (\% of GDP) 1/ & 82.3 & 40.8 \\
\hline 1/ G-20 average uses G-20 debtor countries only \\
Sources: IMF staff calculations, World Economic Outlook and GFS \\
\hline
\end{tabular}
government interest payments as in other countries.

Much of the parameterization for Australia's behavior is the same as the other advanced economies in G20MOD. This is the standard approach to calibration for parameters such as the intertemporal elasticity of substitution (governing the dynamics and speed of the current account response because of the shift between consumption and private saving) and the share of LIQ households, which is at 35 percent, as with the other advanced countries in G20MOD. Similarly, the price and wage Phillips' curves (lead and lag on inflation; the output gap) are calibrated the same as the non-European advanced economies, and the financial accelerator matches that of the other advanced economies.

\section{Fiscal Rules}

Fiscal rules in G20MOD have both a short-term and long-term component. The short-term component is automatic social transfers, whereby the level of general lumpsum transfers is negatively correlated with the output gap, given shifts in other tax bases and spending components, as found in Girouard and André (2005), Table 9. The average value of this correlation for advanced OECD countries is 0.44 , while that of Australia is 0.39 . The long-term component is either the general consolidated government deficit or debt as a ratio of nominal GDP. The deficit-to-GDP target is used for the strict BBR, and the debt-to-GDP target for the strict DR. The Government sets its deficit or debt as a target ratio to GDP (with an additional adjustment for the short-term automatic social transfers) and by choosing to adjust one instrument such that the government budget constraint always holds. The flexible rules move the adjusting fiscal instrument based on the deviations of the actual deficit- or debt-to-GDP ratios from their targets (a deficit or debt gap). The lower the weight on a deficit or debt gap, the longer it takes for a rule to achieve its target. 
The flexible BBR and DR have more complex structures and calibrations. For a flexible rule, the deficit is endogenous, and a chosen instrument reacts directly to the deficit and/or debt gap. For the flexible BBR, there is only a weight on the deficit gap, of 0.8 . For the flexible DR, there is a weight on both the debt gap and the deficit gap. The weight on the debt gap is the inverse of the number of years ( 0.1 for 10 years, 0.2 for 5 years), which controls the rate at which debt returns to its target. The weight on the deficit gap is 0.25 , with the flexible DR using the first difference of the debt-to-GDP ratio to help minimize the general volatility of the economy as the debt-toGDP ratio adjusts.

\section{The Medium-Term Fiscal Strategy}

Broadly speaking, the medium-term fiscal strategy is to encourage economic growth through sensible spending, and revenue growth resulting from good policy, not outright tax increases. Specifically, this entails that the Commonwealth government achieve budget surpluses, on average, over the business cycle. There are four policy elements (Commonwealth of Australia, 2017, Statement 3, p. 7):

- "investing in a stronger economy by redirecting Government spending to quality investment to boost productivity and workforce participation;

- "maintaining strong fiscal discipline by controlling expenditure to reduce the Government's share of the economy over time in order to free up resources for private investment to drive jobs and economic growth, with: the payments-to-GDP ratio falling; stabilizing and then reducing net debt over time;

- "supporting revenue growth by supporting policies that drive earnings and economic growth; and

- "strengthening the Government's balance sheet by improving net financial worth over time."

This version of the medium-term fiscal strategy only dates to 2016, but its principles have been in place since before the global financial crisis - balancing the budget over the cycle, stabilizing and/or reducing spending and taxes, reducing net debt and increasing net worth. With the stark deterioration of the Government's fiscal position in the wake of the global financial crisis, an additional short-term concept was introduced after FY2008/09 - that of budget repair. Below is an evaluation of the performance of the Government in meeting its strategy. 


\section{A. Performance Before the Global Financial Crisis}

Before the global financial crisis, Australia was a beneficiary of the global commodity boom, creating favorable initial conditions for a balanced budget rule motivated by the Charter. The economy was broadly at capacity and growing at potential, and the budget was already in surplus. This further strengthened fiscal sustainability, creating ample fiscal buffers. Indeed, except for FY2001/02, the balanced budget objective was always met with ease (Figure 1). This created very favorable debt dynamics, and the Government started to accumulate net assets from FY2003/04, with net asset-to-GDP ratio peaking at 7.3 percent in FY2007/08 (Figure 2).

Figure 1. Fiscal Balances 1/

(In percent of GDP)

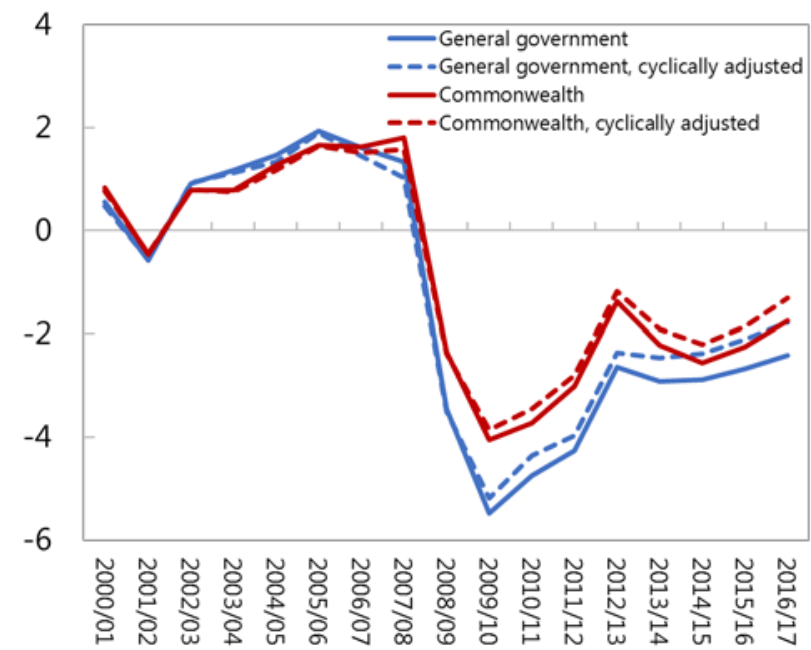

Sources: ABS; IMF staff estimates

$1 /$ General government is consolidated for Commonwealth, State/Territorial and Local levels
Figure 2. Debt Dynamics 1/

(In percent of GDP)

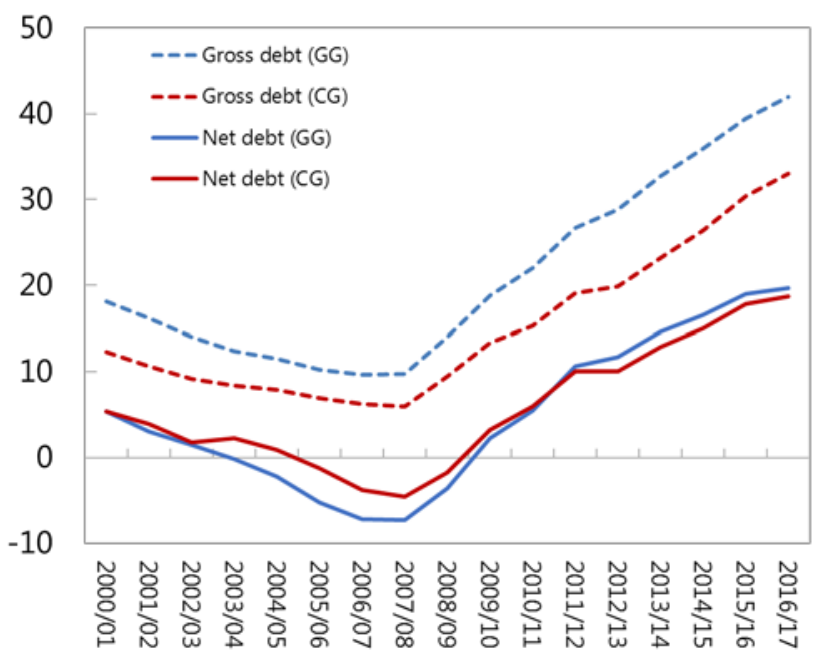

Sources: ABS; IMF staff estimates;

1/ GG = Consolidated General Government; CG = Commonwealth Government 
Figure 3. Cyclically Adjusted

Primary Balance and Stability $\mathbf{1 /}$

(In Percent)

\section{General Government}

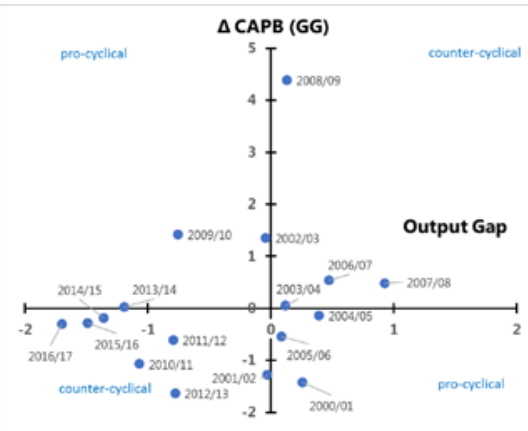

\section{Commonwealth Government}

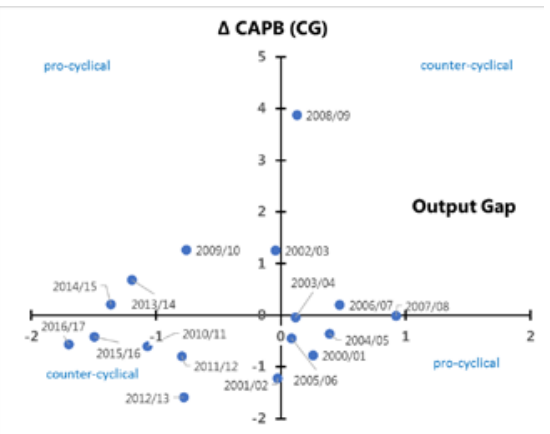

\section{State/Territory and Local Governments}

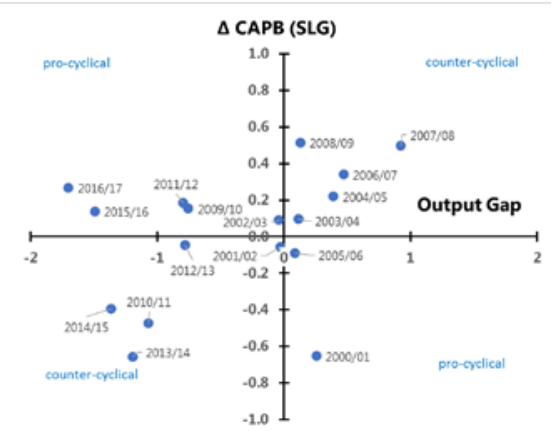

Sources: ABS; Commonwealth and State/Territory Treasuries; IMF staff estimates = Commonwealth Government; SLG = State/Territory and Local Government FY = Fiscal Year $1 / \mathrm{GG}=$ General consolidated Government; CG

In practice, macroeconomic stabilization did not appear to be much a concern, with procyclical and countercyclical fiscal policy alternating in the years prior to the global financial crisis, with a greater emphasis on procyclical spending at the State level (Figure 3).

At the onset of the global financial crisis, with its low debt ratio and considerable fiscal buffers Australia undertook one of the most sizeable fiscal stimulus programs among advanced economies of roughly 4.5 percent of GDP. With this, the Government firmly entered into a period of high deficits, reversing its debt trajectory from FY2008/09 onwards. This necessitated a new auxiliary strategy, based on reducing the deficit, or 'budget repair'

\section{B. Performance Since the Budget Repair Strategy}

Currently, the budget repair strategy is designed to deliver sustainable surpluses as soon as possible, of at least 1 percent of GDP (Commonwealth of Australia, 2017, Statement 3, p. 7), allowing the Government to pursue its medium-term fiscal strategy. The strategy requires that: new spending measures be offset by other spending cuts; unexpected improvements in revenue collections because of economic conditions, be put towards reducing the Government deficit; and decision-making over time is to lay out and maintain a clear path to the desired budget surplus. The budget repair strategy is only to be in place when economic prospects are strong, and unemployment remains low.

Some form of a budget repair strategy has been in place since early 2009. In its Updated Economic and Fiscal Outlook of February 2009 (Commonwealth of Australia, 2009a, pp. 38-39), the Government re-affirmed its commitment to the previous medium-term strategy of achieving budget surpluses, on average, over the economic cycle; keeping taxes as a share of GDP on average below the FY2007/08 level; and improving the government's net financial worth over the medium term. "Allowing tax receipts to recover naturally" and "reprioritizing spending to fast-track the return to surplus," were emphasized. With Budget 2009-10, it explicitly named its emphasis on budget repair as the 'deficit exit strategy,' including the stated rule that real 
expenditure growth was limited to 2 percent in periods with above-trend growth (Commonwealth of Australia, 2009b).

The deficit exit strategy lasted until its replacement with the 'budget repair strategy' in FY2014/15, with an explicit goal of building up to a medium-term balance anchor - a budget surplus of 1 percent of GDP by FY2023/24. For the last couple of years, including Budget 201718 , the horizon for achieving the medium-term anchor has been restated as "as soon as possible." The medium-term projections to the end of FY2020/21 still only see a surplus of 0.5 of GDP, which matches that of the forecasts of the IMF's October 2017 World Economic Outlook for 2021 and 2022 (IMF, 2017).

In the first years after the global financial crisis, budget repair made some progress, with a reduction in the Government deficit to 2.7 percent of GDP by FY2012/13. This was partially achieved on the back of some pro-cyclical fiscal measures from FY2010/11 to FY2012/13, but also as a result of positive effects on from the continuation of the commodity price boom until 2011, which also included strong mining investment, primarily stronger resource tax (petroleum resource rent tax, or PRRT) and CIT collection.

With the commodity price bust, followed by the end of the mining investment boom, Australia's budget repair faltered, as automatic stabilizers pushed up spending, and the Government's revenue forecasts proved to be overly optimistic relative to outcomes (Figure 4). The weak revenue outcomes were largely due to (i) weaker than expected nominal growth which reduced tax gains from PIT bracket creep, meaning that low inflation played a role, not just lackluster real GDP growth; and (ii) the weakening of CIT collection until new revenue streams began to appear after 2016 from the new liquefied natural gas (LNG) and coal mining capacity that was the legacy of the mining investment boom.

Figure 4. Budget Forecasts of Tax Growth (In percent)

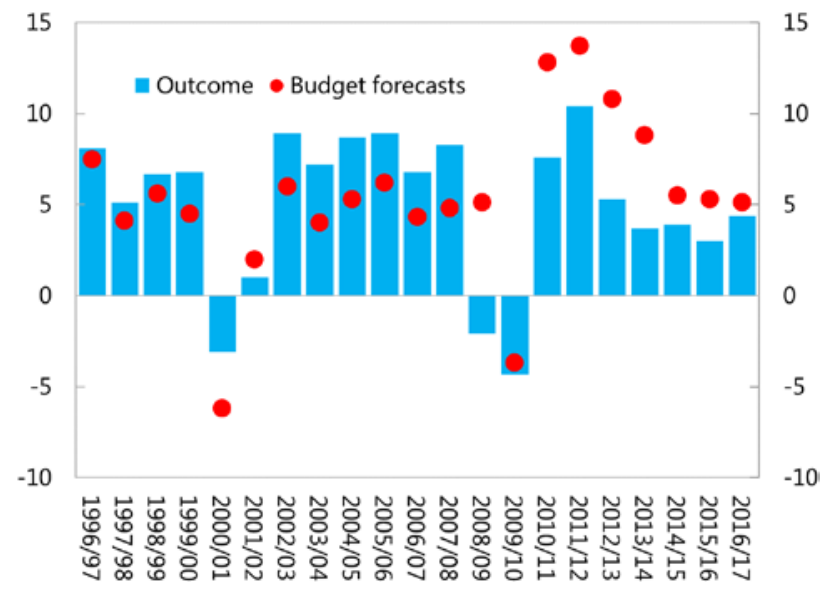

Sources: ABS; Commonwealth Budgets; Treasury of Australia
Figure 5. Commonwealth Gov't Deficits (In percent of GDP)

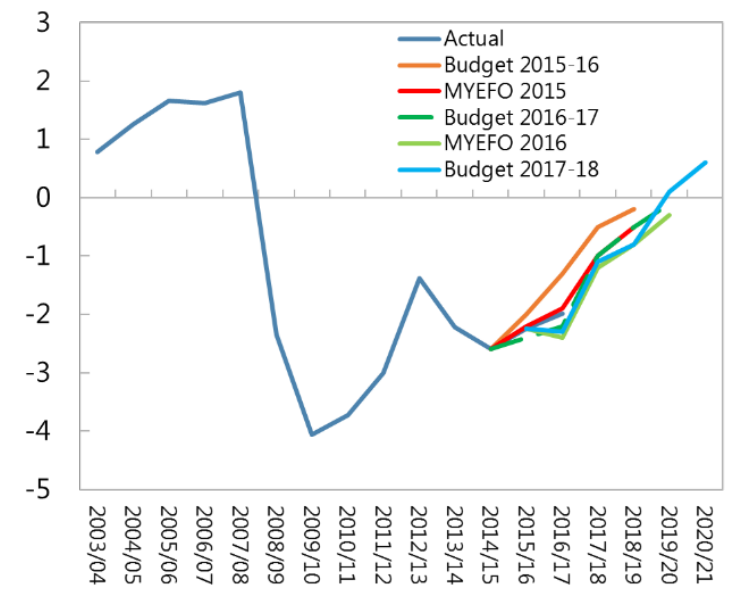

Sources: ABS; Commonwealth Budgets; Treasury of Australia

The Government has attempted to avoid pro-cyclical spending, but it has also entailed a repeated shift of the envisaged trajectory to a surplus of 1 percent of GDP further into the future (Figure 5). However, this shift is sometimes not just the Government missing its revenue forecasts; it 
can also be an explicit policy choice, as was the case in Budget 2017-18, when it decided to increase infrastructure spending at the short-term expense of it budget repair strategy. Such spending can be justified as productivity enhancing, viewed to be still consistent with the medium-term fiscal strategy.

While a postponement of fiscal consolidation may have been warranted on the grounds of economic stabilization, the repeated underperformance against budget plans and the repeated lengthening of the consolidation horizon may have weakened the credibility of the budget repair strategy, and possibly that of the medium-term fiscal strategy. Net debt has increased rapidly after the global financial crisis (Figure 2), followed by some sustainability concerns, at least in the context of Australia maintaining its AAA rating on sovereign debt, particularly since Standard and Poor's placed the Australian sovereign's AAA rating outlook at negative in 2015, although both Moody's and Fitch Ratings have maintained and confirmed their outlooks as stable. Strictly speaking, thus far the current budget repair strategy has not delivered on the promise of the medium-term fiscal strategy.

\section{Performance Under the Budget Repair Strategy Going Forward}

Going forward, the Government continues to rely on the same means of achieving fiscal consolidation. Real payments growth is expected to increase to 2.9 percent over the period from FY2021/22 to FY2027/28, per annum on average, a 1 percentage point higher than the estimated 1.9 percent per annum on average over the Government's forward estimate period (FY2017/18 to FY2020/21). The path for spending is also maintained on its current stable trajectory.

Consequently, there are two probable paths for fiscal outcomes going forward. The first is that of the Government, which sees the successful delivery of the budget repair strategy while still relying on strong nominal growth, an expectation that has not been met in the recent past. The second probable path is one where the consolidation path needed for budget repair is thrown off track. Such a path does not pose much of a problem for the medium-term balance anchor underpinning the current budget repair strategy, as bygones are bygones. While the Government still has a relatively low debt position by global standards, at some point, Australia, being one among other countries that rely considerably on foreign purchases of its debt could face more serious market discipline requiring a refocus on consolidation efforts. But, often this situation arises in a context of procyclical spending coming out of a period of moderate, if not spectacular economic growth (as it has been post-crisis for Australia) and then entering into a recessionary environment which requires countercyclical spending that markets may not be willing to finance - a situation not contemplated under Australia's medium-term fiscal strategy, and its fiscal framework more generally. 


\section{The InTERgenerational Report ANd Long-Term Pressures}

Reaching the medium-term balance anchor and achieving the medium-term fiscal strategy faces further challenges related to demographic concerns. These have been considered already in one other product of the Charter's fiscal framework, the 2015 Intergenerational Report

(Commonwealth of Australia 2015, referred to as IGR 2015 below), which provides one longterm view from the Government of the Australian economy - the Treasurer, to be precise. It is a detailed analytical report aimed at highlighting the long-term fiscal challenges facing Australia, because of the ageing of its population and of other factors likely to boost the demand for some key public services, especially health care and aged care. The IGR 2015 'proposed policy' scenario presents a baseline long-term projection, constructed to highlight the implications for the Government's finances (especially on net debt) from the projected long-term ageing of the population, consistent with the policies active at the time of the Mid-Year Economic and Fiscal Outlook 2014-2015 (Commonwealth of Australia, 2014b). IGR 2015 further considers alternative scenarios where budget repair is not achieved, or higher productivity and labor force participation help stabilize net public debt at moderately low levels of debt. While budgets since IGR 2015 have attempted to address some of these issues, much of the underlying pressures are still valid, and these scenarios are helpful for underpinning the long-term analysis below.

Long-term pressures on the budget - related to primarily demographic issues such as health care, aged care, and pensions - are looming. By 2050, IGR 2015 estimates that the Government will need to spend an additional 2.5 percent of GDP on such outlays, assuming an unchanged policy framework. Even assuming a linear trend starting from zero in 2021, and reaching its long-term value after 30 years, the estimate of extra spending adds up to 21 percent of GDP of net debt by 2050. Moreover, in the very long term, net debt would stabilize after increasing by a whopping 58 percent of GDP. This is referred to below as the 'No Policy Action Scenario.'

Apart from consolidation, there are measures available to the Government that could lessen the pressure on the Australian economy. One way forward is revenue-neutral tax switching by reducing direct taxes - the CIT by 0.7 percent of GDP, the PIT by 1.4 percent of GDP - against an offsetting increase in indirect taxes (GST) of 2.1 percent of GDP, similar to that proposed in Pitt (2015). While tax switching does not prevent the large run-up in debt, it strengthens domestic demand in face of the crowding out effects of increased Government demand for funds in the economy. This is referred to below (and in Box 1) as the 'Tax Switching Scenario', which embeds the No Policy Action Scenario.

Given that this tax strategy does not reduce the debt burden significantly, fiscal consolidation is required to achieve debt control. For simplicity, to contain the costs that could result, there are cuts in other lumpsum transfers, outside of aged care and pensions. The Government adheres to a balanced budget, aside from allowing for the effects of automatic social transfers. This is referred to as the 'Simple Balanced Budget Scenario' which builds on the Tax Switching Scenario.

In the No Policy Action Scenario, real GDP is stronger by less than 1 percent after 30 years despite the strong increase in general transfers, which feed directly into household consumption, 
which increases in the long term by about 2 percent (Figure 6). Not only does the spending have an immediate impact on LIQ households, but it also changes the consumption profile of OLG households, given the inevitable and inexorable path of spending increases. Private investment, on the other hand, suffers as it is crowded out by government debt, holding roughly at its baseline level in the long term. Nonetheless, the additional consumption demand stimulates the supply side of the economy, and increases demand for labor as a factor of production.

The new spending increases government debt, which is dissaving, increasing the demand for foreign financing, with little change in GDP overall. This increases the Australian net foreign liability position further, by about 20 percent of GDP, and lowers the current account, thereby supporting a notable real appreciation of around 2 percent relative to baseline in the long term. There is a rebalancing between the domestic and external sectors, with a worsening net trade balance offsetting the strength in consumption. Overall, real GDP barely changes.

Under the Tax Switching Scenario, the long-term positive effects of PIT and CIT cuts are greater than the equivalent increase in the GST and confer strong positive effects on real GDP (Box 1). The CIT cut has a direct positive impact on investment demand, while the PIT cut works to increase labor supply and income. Indirect effects from PIT and CIT also play an important role in decreasing costs for firms, stimulating potential output, and generating positive effects on wealth through the capital stock and labor income. The GST increase works against consumption, and offsets some of the positive impacts of both the PIT and CIT cuts. In aggregate, consumption gains 0.5 percentage point, and investment gains 4.0 percentage points so that real GDP is about 1.4 percentage points higher, all relative to the No Policy Action Scenario.

Since the tax switching acts as a positive supply shock, the output gap goes into excess supply before rising as the expansion becomes more general. However, there are positive inflationary pressures from higher demand on impact, leading the RBA to increase the overnight cash rate by over 50 basis points to maintain inflation on target. In the short term, the RBA could play a role in amplifying the positive effects from the tax switching regime by changing the overnight cash rate, thereby preventing some of the rebalancing against the domestic sector.

Under the Balanced Budget Scenario, a key channel is the crowding in of private investment, as private saving and foreign assets are no longer being diverted to the government. Furthermore, the embedded tax switching acts to arrest the rebalancing of the economy towards the external sector, encouraging an expansionary real exchange rate depreciation of 1.2 percent relative to baseline in the long term. Import compression occurs, but is offset by the expansion of private investment, which happens to be more import-intensive than household consumption. 
Figure 6. Long-Term Spending Pressures

(Percent deviation from baseline, unless otherwise stated)

No policy action to offset spending pressures

Add tax switching by reducing income taxes and increasing GST

Add a balanced budget with help of general transfer adjustments

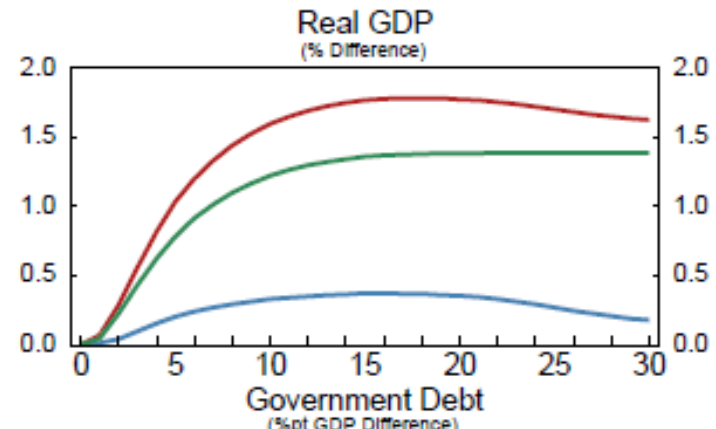

Output Gap
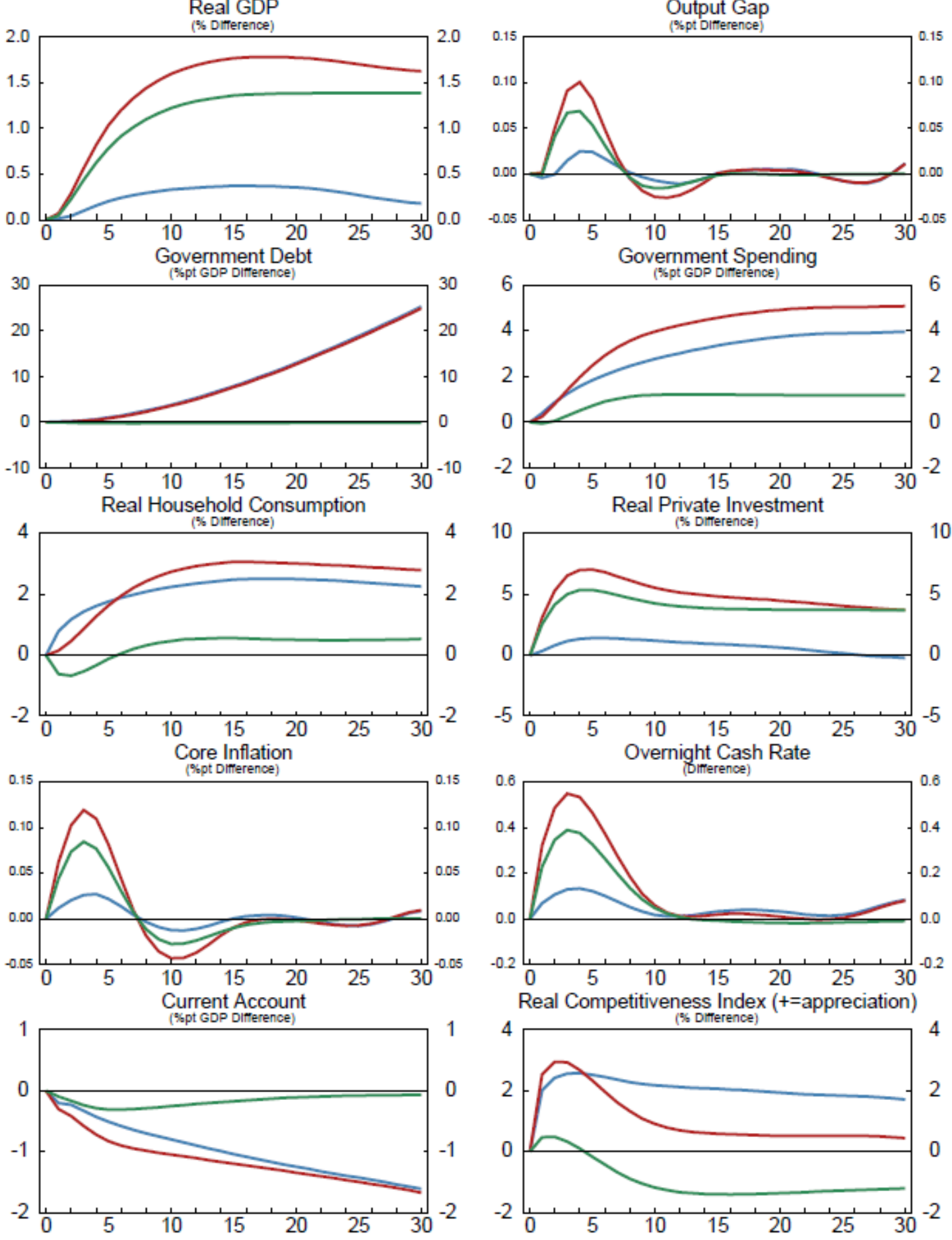

Source: IMF staff calculations. 
Going forward, the No Policy Action Scenario will be referred to as the Benchmark Scenario. To summarize, under the Benchmark Scenario, if nothing is done to offset future spending pressures, net government debt and the net foreign liabilities position deteriorate in the medium term. Under such a benchmark, additional possible risks, such as sovereign risk premia that would raise the government's borrowing costs, and possibly that of the economy as a whole, (which would further crowd out investment and discourage consumption) are not explored.

Box 1. Decomposition of the Tax Switching Scenario

The tax switching scenario is decomposed into two components. First there is a switch from the CIT to the PIT (on both wage and dividend income) of 0.7 percent of GDP. Second, there is a further switch from PIT (on wage income alone) to GST, of 2.1 percent of GDP. A roughly linear combination of these two switches produce the results for the Tax Switching Scenario in Figure 6. A key point to remember that PIT is not only payable on all households' wage income, but also on dividend income, exclusively received by OLG households.

First, consider the switch from CIT to PIT. When the CIT is cut, OLG households will receive fewer 'franked' dividends, and automatically face a greater tax liability for their dividend income (see the fiscal section of Appendix I for a discussion of franking). There will be only a slight increase in taxes on wages, and dividend income will bear the brunt of the PIT increase. When the cut in CIT is netted with the aggregate increase in PIT, the increase in investment outweighs the direct negative impact of the PIT shift on consumption, which is offset within the first 5 years.

Second, consider the further switch from PIT to GST. For the second part of the scenario the wage portion of the PIT is decreased (instead of increased), in order to offset it with a 2.1 percent of GDP increase in the GST. Because the GST increase dampens consumption for both OLG and LIQ households immediately, but the PIT cut serves to stimulate it, the effect on real GDP is relatively weak at 0.3 percent of GDP - which translates into a small multiplier of 0.14 . This is in line with work presented by the Treasury (Commonwealth of Australia, 2016). 


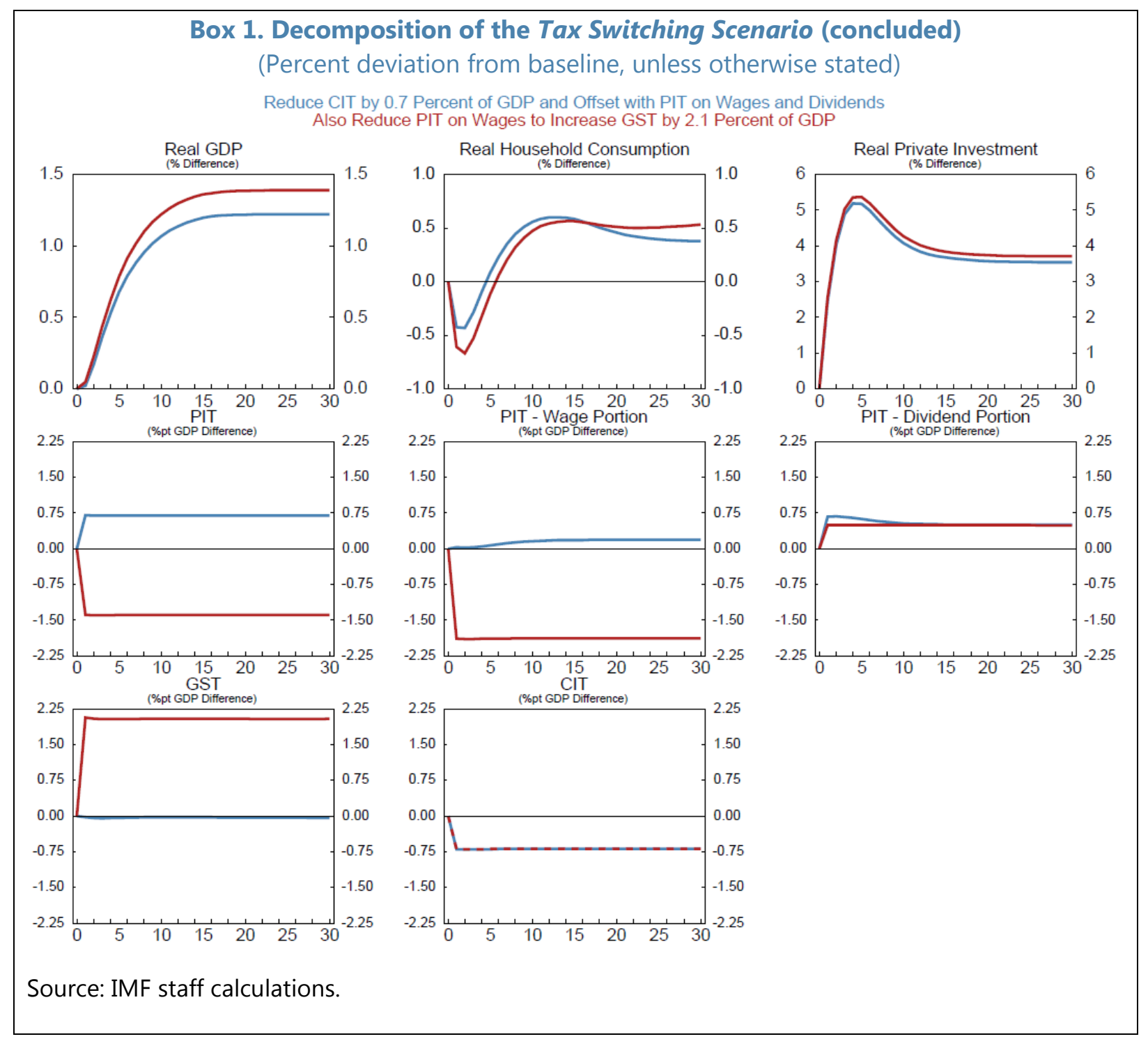

\section{A Model-Based Analysis of Fiscal AnChors}

In addressing issues with the budget repair strategy, and with debt sustainability in the face of rising demographic pressures as highlighted by the IGR 2015, a long-term debt anchor is compared against the current medium-term balance anchor. In illustrating, an environment is first constructed where the benchmark scenario and the associated increasing debt profile is adopted from the previous section which is then followed by examining the reaction of the economy to the implementation of the long-term anchor over the medium-term horizon of 2021 to 2050. Tax switching is maintained in attempt to better position future fiscal actions. The method employed interacts with a 'debt norm' analysis which we consider to be a reduction of net government debt by 10 percent of GDP though not to be taken as advocating a particular (optimal) long-term level of net debt but rather a means to elucidate the analyses which follow. 
Three analyses are undertaken. First, the efficacy of a long-term debt anchor is compared to that of the medium-term balance anchor from the budget repair strategy, using three illustrative scenarios: (i) an unexpected and substantial pick-up in aggregate demand; (ii) a boom-bust cycle related to swings in the global price of metals; and (iii) a "new mediocre" scenario (described below), all three are evaluated against a set of (five) metrics for debt sustainability and economic stability. Second, different fiscal rules to implement the long-term debt anchor are explored, based on combinations of expenditure and debt rules under differing speeds of adjustment to achieve the debt norm. Third, in operationalizing a long-term debt anchor and in determining how each fiscal rule would perform, two scenarios (the aggregate demand and the boom-bust cycle) are evaluated under the benchmark scenario, using the same metrics.

\section{A. The Argument for a Long-Term Debt Anchor}

A long-term debt anchor provides certainty for households and firms in their decision making. Just as price stability removes uncertainty about the nominal economy, an explicit debt target can remove a significant source of uncertainty about the real economy. Government debt is a vital part of wealth holdings by households. It also crowds in or out net foreign liabilities (through its flow, the current account) and capital stock (through its flow, investment). Therefore, a long-term debt anchor (a stock concept) helps stabilize the Australian economy in a way which the medium-term deficit anchor (a flow concept) might not.

Conversely, the medium-term balance anchor introduces uncertainty as it has no mechanism to prevent the drift of government debt. Whenever there are shocks to the economy, even if the economy starts at the medium-term balance anchor, returning to the medium-term balance anchor will result in net debt drifting. In the current environment, with shocks skewed to the downside, net debt would most likely drift upwards. Although net debt could follow a random walk under a balance anchor in the long term, this is unlikely in the short term. Moreover, the question of uncertainty, or poor outcomes, are less state dependent than under the medium-term balance anchor.

To assess whether the long-term debt anchor can perform better than the medium-term balance anchor, G20MOD can be used to produce economic shock scenarios which require the government to employ its fiscal policy rule that aims to maintain its (medium-term or long-term) anchor. Below are three illustrative scenarios that cover both demand and supply disturbances, that can be regarded as possible upside and downside risks:

1. A temporary but substantial increase in aggregate demand (Box 2). This assumes that aggregate demand turns out to be stronger than expected by about 2 percent of GDP at its peak in year 3 .

2. A terms-of-trade-driven boom-bust cycle (Box 3). A term-of-trade boom-bust cycle is built by imposing a path of real global metals prices that loosely matches the changes in the RBA's Index of Commodity Prices (ICP).

3. The "new mediocre" (Box 4): The combined secular stagnation and permanent negative terms-of-trade shock are considered. While a risk, it can be argued that it may not unfold 
for years to come. It is important to understand that the shock is a negative one to future expectations, and not a well-incorporated and understood decline in outcomes by forward-looking households and firms.

Three different fiscal rules are analyzed to draw conclusions. The first rule maintains the medium-term balance anchor, held over the course of the business cycle, which is labelled as a flexible BBR over 7 years (labeled 'flex BR' in Table 3 below). The other two rules are different formulations of debt rules (DR) to maintain the long-term debt anchor - one strictly holds debt at its target (labeled 'strict DR') and the other pursues the debt target flexibly over with a 10-year horizon (labeled 'flex DR (10yrs)'), in Table 3 below.

Evaluating the relative performance of the fiscal rules is based on five indicators. As guiding principles, rules are evaluated against achieving debt control (debt reduction along a debt norm path) and economic stabilization (primarily their degree of countercyclicality) (see Kinda, 2015 for a basic application of the methodology). Debt control should have a degree of flexibility, which is measured by the root mean squared deviation (RMSD) from the debt norm; the further from 0 , the more debt can respond under a rule to any given shock and minimize additional adverse impacts on real GDP. Debt control is also a matter of precision, measured as the deviation from target in a specific year (here, 10 years by 2030) and by the absolute mean deviation (AMD) of debt from the debt norm path where closer to 0 is better. Economic stabilization can be captured by the variability of real GDP over 10 years (where closer to zero is better) and by a measure of procyclicality.

Box 2. A Temporary but Substantial Increase in Aggregate Demand

Consider a temporary but substantial increase in aggregate demand. Real GDP peaks at over 1.6 percent above the baseline in the third year. Investment movements are significantly more sizeable than consumption (in the order of four times) relative to baseline. The government deficit moves in tandem with changes in revenues and expenditures - tax rates are exogenous, as is spending, except for the automatic social transfers.

Monetary policy plays a key role. As the economy enters excess demand (the output gap is greater than zero), there are upward pressures on inflation, which are addressed by the RBA in achieving its mandate of price stability. They increase the policy rate by 2 percent by the second year, and maintaining a tightening stance into the fifth year.

Economic growth results in a strong debt consolidation. The government deficit falls by almost 0.9 percent of GDP in the second year.

Elsewhere in the economy, the external sector worsens. Import demand is higher, encouraged by the upward pressure exerted by monetary policy on the real exchange rate. Here, the government is assumed to achieve the fiscal policy rule by reducing social transfers, meaning fiscal policy is countercyclical and works against the increase in aggregate demand. 
Box 2. A Temporary but Substantial Increase in Aggregate Demand (concluded)

(Percent deviation from baseline, unless otherwise stated)

Medium-Term Balance Anchor

Long-Term Debt Anchor $=$ Strict DR over 10 Years

Long-Term Debt Anchor = Flexible DR over 10 Years
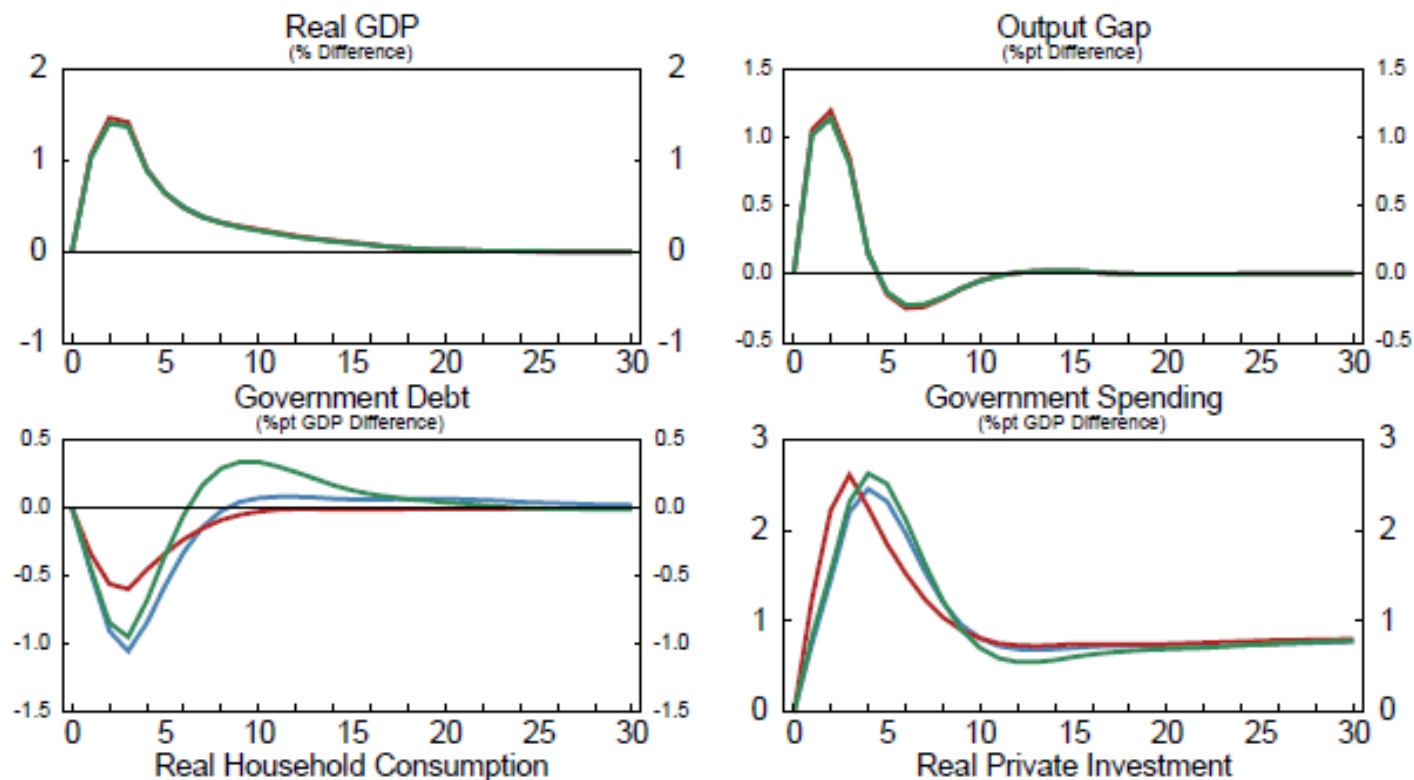

(\%pt GDP Difference)
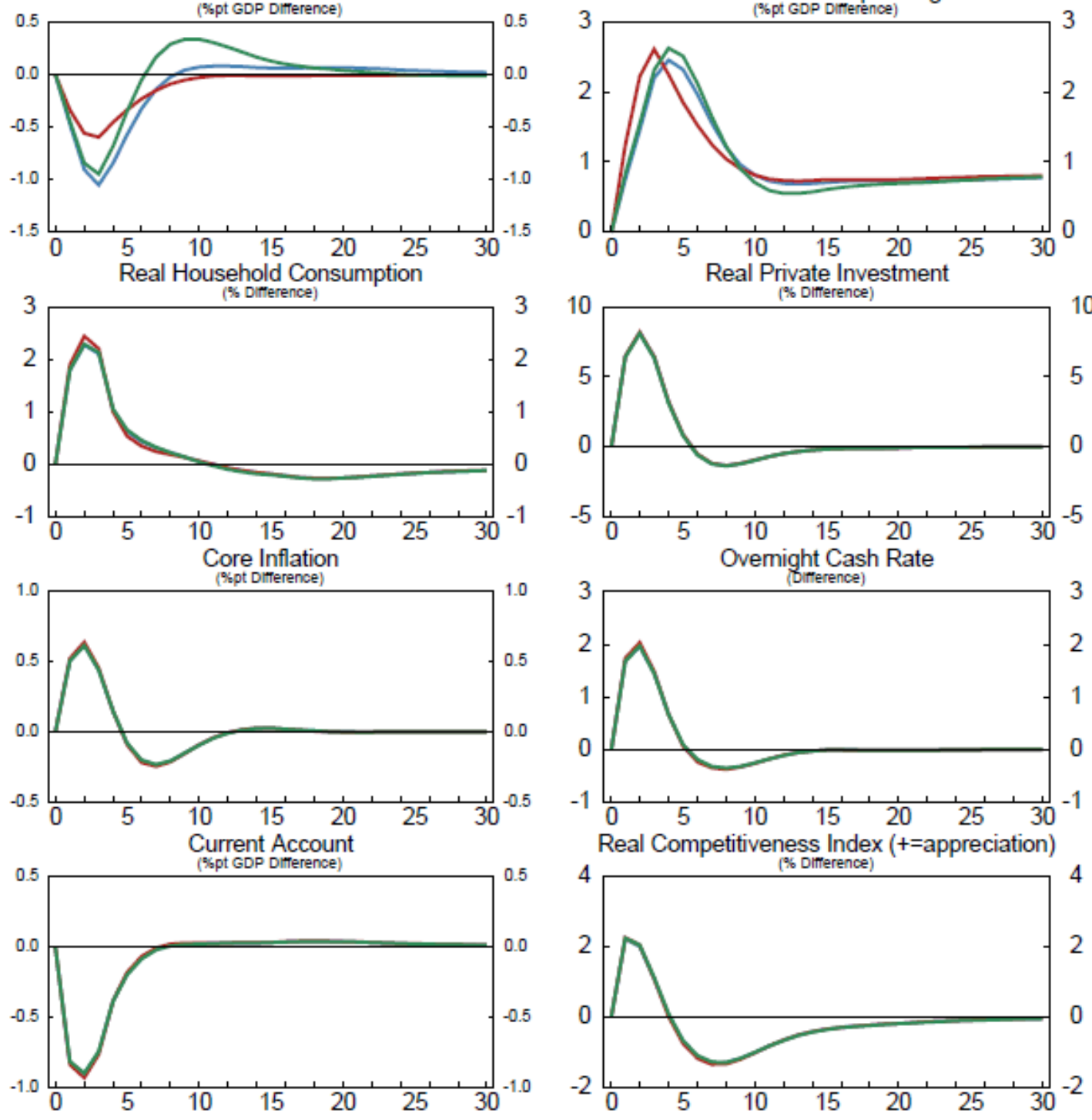

Source: IMF staff calculations. 
Box 3. A Terms-of-Trade-Driven Boom-Bust Cycle

The terms-of-trade-driven boom-bust cycle causes substantial disruptions over the first ten years. As is the case with most boom-bust cycles, during the boom years there is only an expectation that commodity prices will stabilize; there is no prescience of a collapse (as in Rees and others, 2015). This makes the downturn that much more disruptive for the economy in general, and investment in particular. The government deficit moves in tandem with changes in revenues and expenditures - tax rates are exogenous, as is spending, except for the automatic social transfers.

The boom-bust cycle is strongly reflected in real GDP fluctuations. There is a continuing upward expansion in the first 4 years, then as real global metals prices unexpectedly unwind and undershoot their long-term trend, real GDP weakens and contracts before strengthening to return to its trend path after about 10 years.

In the first part of the cycle, there are highly expansionary wealth effects which encourage private investment. The follow-up contraction leads to a fall in investment, falling to 2.6 percent below baseline in the sixth year from its peak of 2.2 percent above the baseline in the third year. Investment is also the driver for the behavior of imports. Note that the investment response is different from the current boom-bust cycle, which had a large infrastructure component for mining. It is assumed that the current infrastructure will be sufficient to accommodate another boom, and will not cause an additional investment response.

The rapid appreciation is part of the commodity price cycle, which generates a wealth transfer to commodity exporters such as Australia, while the converse is true during the downturn, with a large depreciation. In the case of non-mining exports, the real exchange rate is the dominant influence, so they first contract during the economic boom, and expand during the downturn. Therefore, non-mining exports are countercyclical and help stabilize the economy to some degree.

Monetary policy works to smooth the cycle. Since a boom-bust cycle is a classic aggregate demand shock, inflation first rises then falls, meaning that the cash rate cycles in the same way, peaking at +50 basis points in the second year, before troughing at -50 basis points in the fifth year, relative to baseline. 
Box 3. Terms-of-Trade-Drive Boom-Bust Cycle (concluded)

(Percent deviation from baseline, unless otherwise stated)

Medium-Term Balance Anchor

Long-Term Debt Anchor $=$ Strict DR over 10 Years

Long-Term Debt Anchor = Flexible DR over 10 Years
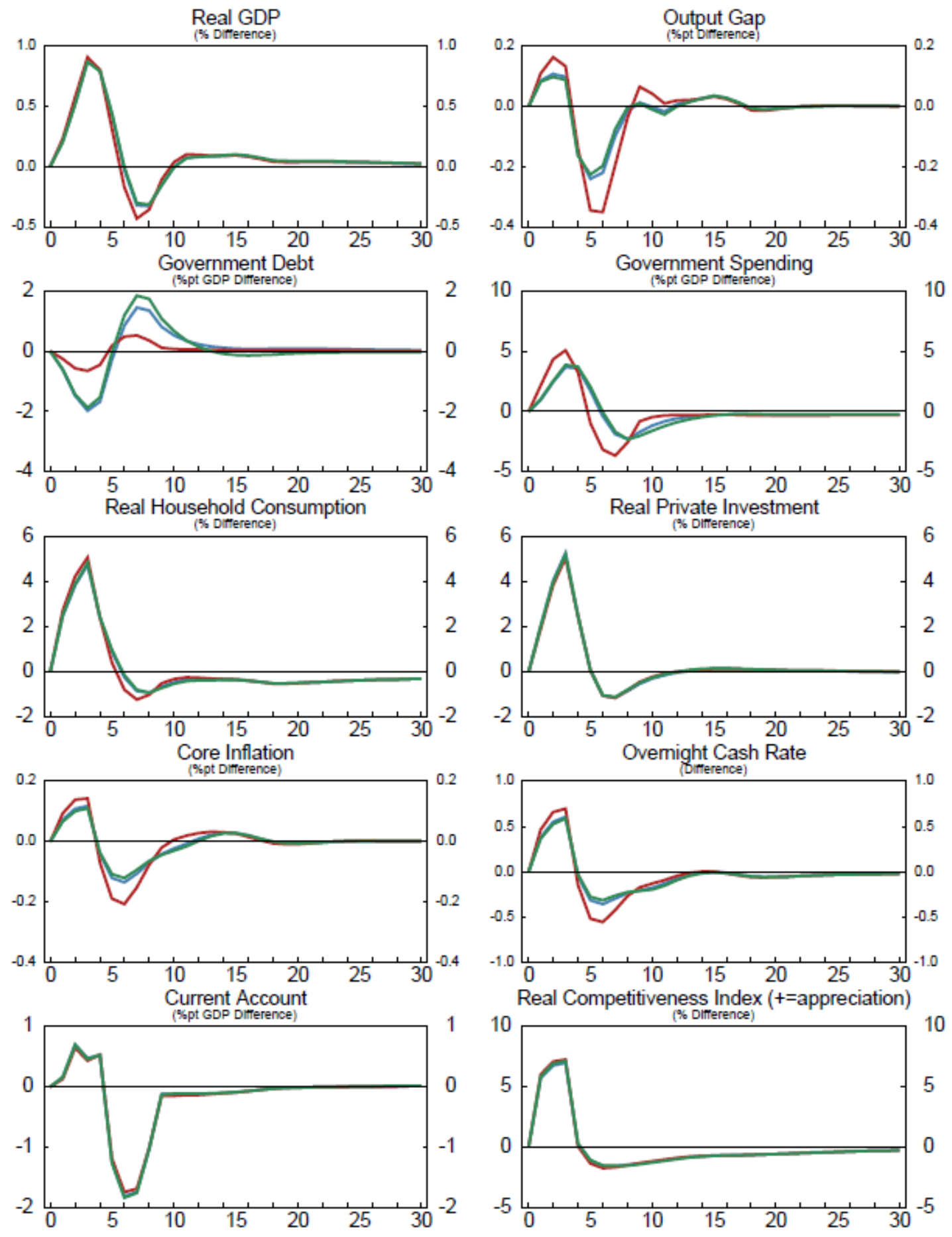

Source: IMF staff calculations. 
Box 4. The "New Mediocre" and its Implications on Australia

The illustrative version of the "new mediocre" considered here is summarized in the accompanying figure. In the case of Australia, it can be described as secular stagnation, where households and firms realize that future productivity will be lower than originally expected. On a global scale, secular stagnation permanently drives down global metals demand, which is a negative terms-of-trade shock for Australia. The government deficit moves in tandem with changes in revenues and expenditures - tax rates are exogenous, as is spending, except for the automatic social transfers.

The "new mediocre" is basically a realization that ongoing productivity growth will be lower than originally anticipated by households and firms. It is akin to a negative productivity shock. There is lower demand for factors of production, so the capital stock and investment contract. There is also lower labor income and wealth. Goods cost more to produce, lowering consumption for a given level of income, leading to a contraction of real GDP. The Australian dollar also appreciates by about 1.5 percent, so supply contracts in response, and there is a shortage of goods to meet foreign demand.

This is exacerbated by a decline in the global price of metals resulting from weaker global demand, negatively affecting Australia's terms of trade. There is a further contraction of metals production from the lack of global demand and price pressures that make it more difficult to meet production costs. This is a negative wealth shock, with negative implications on consumer spending, and harmful second round effects. Overall, real GDP contracts by 1.5 percent relative to baseline after 10 years, led by large declines in consumption and investment (2.1 and 2 percent, respectively).

The Government also faces strains in its balance, and monetary policy is assumed to have room for easing. The Government faces higher spending from automatic social transfers, and downward pressure on tax revenues resulting from both a general contraction of the tax bases and weaker royalties and resource taxes. This raises the deficit by 0.5 percent of GDP by the second year, and 0.8 percent of GDP by the tenth. In playing a supporting role to weaknesses in demand, monetary policy is deployed with the RBA only needing to cut the overnight cash rate by around 30 basis points at its trough in the second year. With an increased probability of hitting the effective lower bound on interest rate, the RBA may be constrained in cutting rates further. Moreover, since this is a negative permanent supply shock, the RBA can only smooth, but not prevent, the downward decline in the economy. 
Box 4. The "New Mediocre" and its Implications on Australia (concluded)

(Percent deviation from baseline, unless otherwise stated)

Medium-Term Balance Anchor

Long-Term Debt Anchor $=$ Strict DR over 10 Years

Long-Term Debt Anchor = Flexible DR over 10 Years
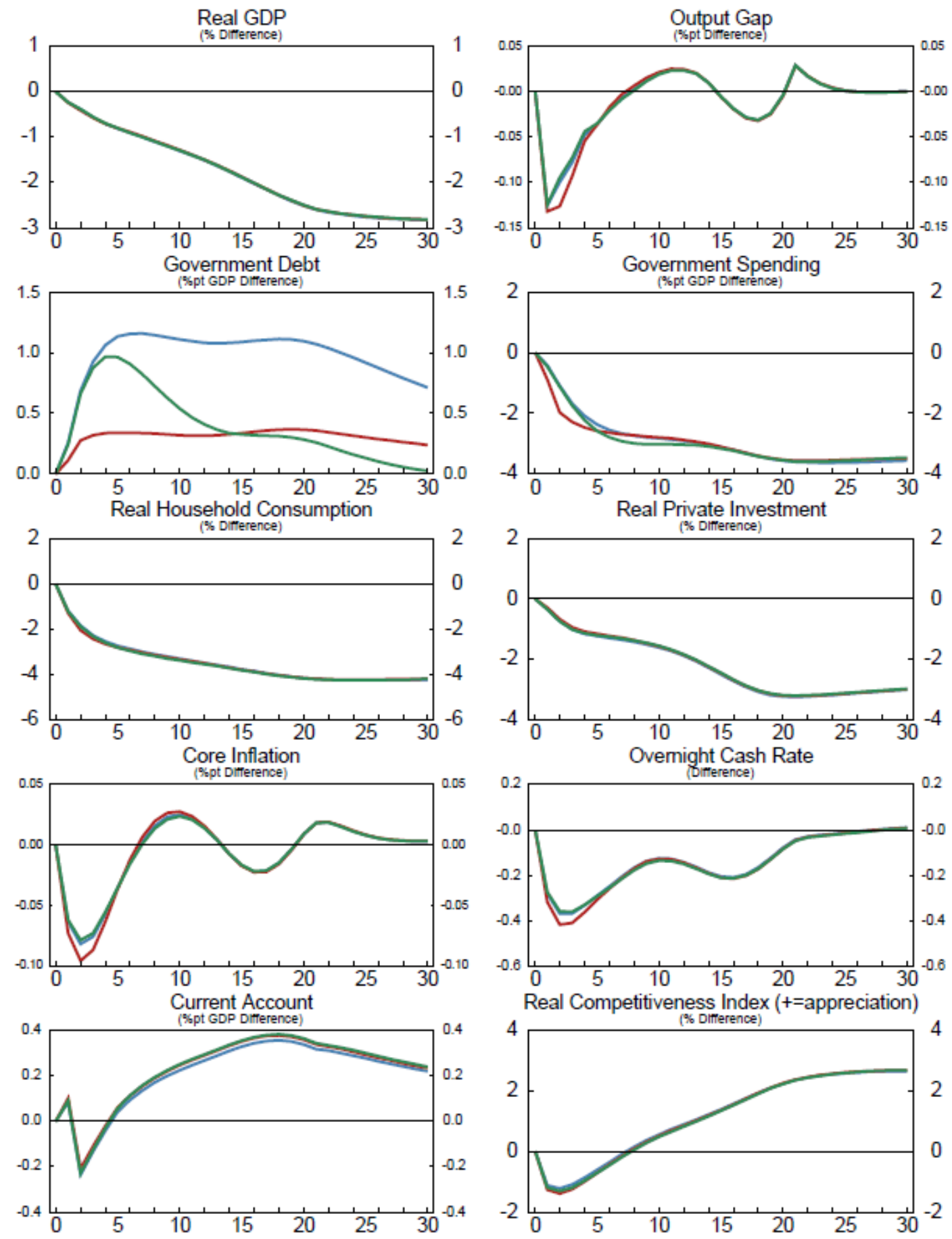

Source: IMF staff calculations. 
The measure of procyclicality is centered around zero, comparing the change in the primary surplus with that of the change in the output gap. Fiscal policy is considered procyclical if the output gap becomes more positive (negative) and primary surplus decreases (increases). The preference is for countercyclicality, where the primary surplus and the output gap are positively correlated, and fiscal policy works on smoothing business cycle movements, providing economic stabilization.

Table 3 summarizes the results. The RMSD ([1] of the criteria in the table) shows that there is more flexibility (debt would respond better to shocks) under the flexible debt rule, as can the medium-term balance anchor. The debt rule is more precise in the long term, as shown by the lower value for the AMD [2] for both debt rules. Real output is less variable under the debt rules [5] implying more certainty of the outcome and more rapid adjustment on the part of households and firms as they make their behavioral choices. By design, the DR achieves faster convergence to the desired debt-to-GDP ratio [3], more consistently under the strict DR. While the mediumterm balance anchor is more countercyclical, the flexible DR also demonstrates notable countercyclicality [4]. Even though the results do not adequately capture the uncertainty inherent in the long-term end-point in the announced medium-term balance anchor, the longterm debt anchor under the flexible DR performs relatively strongly.

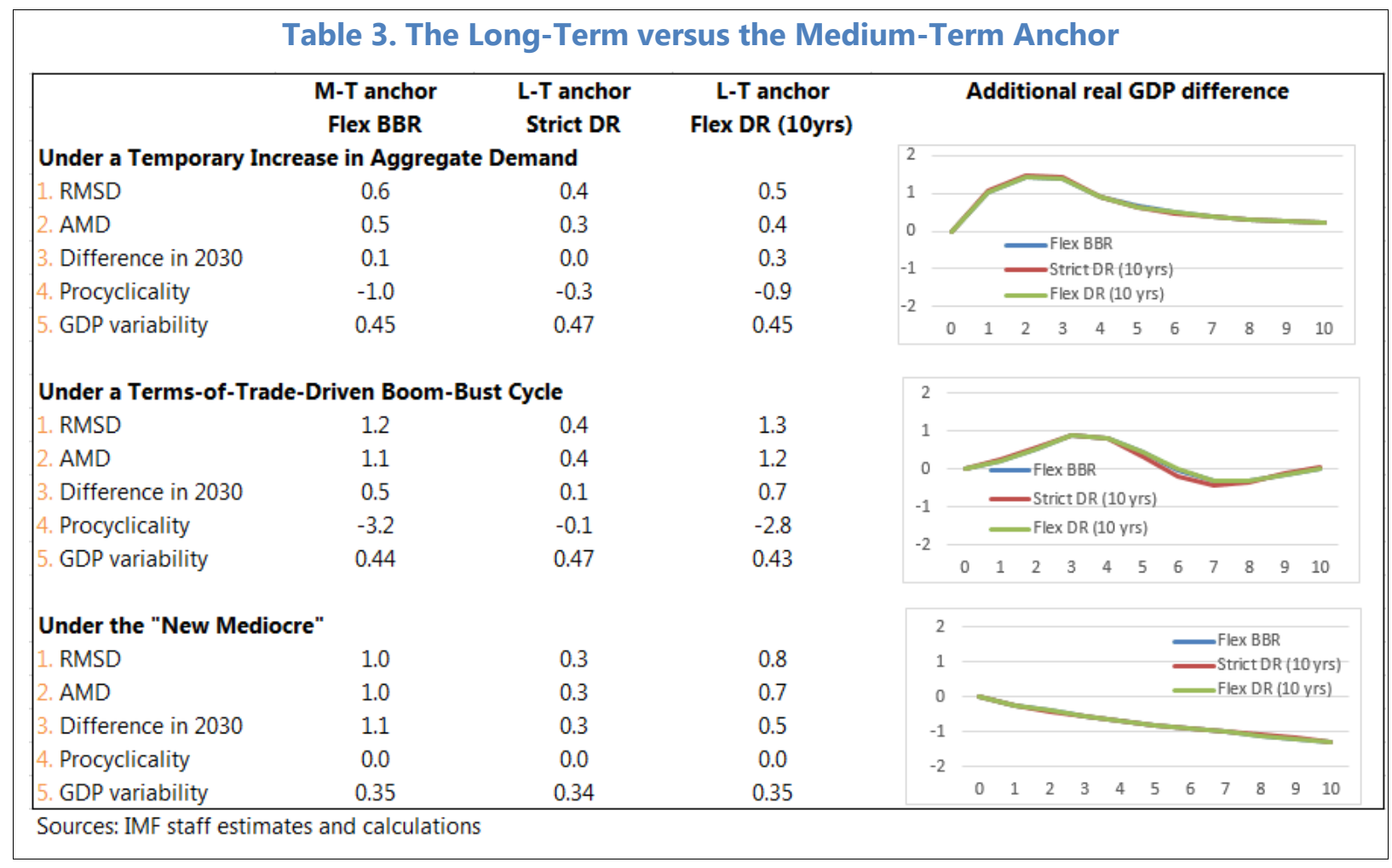

\section{B. Implementing the Long-Term Debt Anchor with Fiscal Rules}

An aggregated fiscal rule, that is a composite of component fiscal rules, is an effective method to operationalize a long-term debt anchor, provided it is appropriate to macro-fiscal conditions and institutional settings. In practice, if fiscal consolidation is the Government's goal, as it is 
with the current budget repair strategy, a fiscal rule should support both macro and fiscal stability. The outcome should be that real GDP would be higher and debt would be expected to be more sustainable than otherwise.

The rationale for adopting legislated numerical fiscal rules can be weaker in a country like Australia. It has a well-established record of responsible fiscal policies under Governments of different political ideologies. The question is how do the potential benefits of a clearly and specifically defined fiscal policy targets backed by a stronger legal basis compare with their potential costs. Fiscal rules are not a panacea - they involve delicate trade-offs between ensuring inter-temporal consistency in the conduct of fiscal policy, and garnering an appropriate degree of flexibility in fiscal management (ensuring a scope for countercyclical policy and the full operation of automatic social transfers). These trade-offs can be moderated, through an appropriate design of the rules, such as the inclusion of escape and revision clauses. Such flexibility generates better growth and debt outcomes, and governs the choices on the rules implemented below.

The aggregated fiscal rules are analyzed under an intuitively constructed environment. The medium-term target horizon extends between 2021 and 2050, taking the benchmark scenario as given, with its large run-up in debt. Tax switching is implemented to better position future actions by the Government. The analysis is based on a 'debt norm', defined as a reduction in net debt of 10 percent of GDP relative to the benchmark scenario, in better tracking the costs and benefits under consideration. This will be treated as the 'benchmark consolidation' case.

Three candidate aggregated rules are constructed, their components drawn from the different types of fiscal rules, as defined in Section II.C. Guided by both Budget 2017-18 and IGR 2015, the analysis focuses on the component rules deemed most relevant to the Australian situation:

- An expenditure rule (ER). Government consumption and general transfers are assumed to grow at only 2 percent a year for 10 years starting in 2021, roughly consistent with the average over the WEO horizon extending from 2016 to 2020. This is also in line with the Government's stated goal of reducing the size of government. Relative to Budget 2017-18, this means a reduction spending growth by 0.9 percentage points each year.

- Variants of a debt rule (DR). The long-term government debt target is met after 5 or 10 years by varying the GST rate to achieve the debt norm of 10 percent, with either a strict or flexible pursuit of the debt norm path from 2021 to 2050.

These are combined in the following manner:

- $\boldsymbol{E R}+$ strict $\boldsymbol{D R}$, where 90 percent of debt norm is achieved by 2030, with a strict adherence to the debt target each year;

- $\boldsymbol{E R}+$ flexible DR, where 90 percent of debt norm is achieved by 2030 (over 10 years) allowing for some variability in debt that is consistent with an average business cycle frequency of six to seven years, further implying an average decrease in the deficit of around 1 percent of GDP relative to the 'benchmark scenario'; and 
- $\boldsymbol{E R}+$ flexible DR, where 90 percent of debt norm is achieved by 2025 (over 5 years) allowing for some variability in debt that is consistent with an average business cycle frequency of six to seven years, and an average decrease in the deficit of around 2 percent of GDP relative to the 'benchmark scenario'.

In the benchmark consolidation, real GDP is always stronger, thanks to the embedded tax switching strategy (Figure 7). However, there are short-term downward pressures from the consolidation. The profiles of real GDP depend on the rule in force. The shorter time horizon of 5 years inflicts the largest short-term costs, while the more flexible rules allow real GDP to react positively to the tax switching, with debt reacting more gradually to it and to the expenditure rule.

The components of domestic demand act at cross purposes in the short term. Consumption is weakened by the increase in GST to pursue debt reduction, dominating the positive effects from the PIT cut. At the same time, private investment is stronger because of the lower CIT, with further crowding in from the reduction in government dissaving. This dichotomy is reinforced by the DR with 5-year adjustment.

In the short term, monetary policy acts as a drag, except under the five-year horizon. The RBA works to maintain its inflation target, which smooths the path of real GDP. The GST is increased so much under the DR that weakness in consumption is disinflationary, and the RBA increases the overnight cash rate less on impact, followed by further cuts in the medium term.

In the long term, the components of domestic demand move in one direction. The positive investment effect as exhibited over the short term continues, and helps expand the productive capacity of the economy, leading to higher labor demand and wages. With the increase in labor income and wealth, consumption flips to contribute positively to GDP, as is the case with private investment.

The reduction in government debt means that there are less domestic assets available to households. To maintain a certain desired level of financial wealth, households would demand more foreign assets, which implies a higher current account to accumulate those assets, especially in the short term. Furthermore, the real exchange rate depreciates as more goods are available that need to be sold abroad.

These results are stronger when the debt rule is more aggressive, pursuing the five-year horizon to meet the target. The faster convergence to the long-term debt target implies changes in economic flows occur rapidly in the first several years. As noted above, since GST is the adjusting instrument, this further reduces consumption in the short term and lead to looser monetary policy and stronger private investment. The faster government dissaving leads to a quicker real exchange rate depreciation, with larger current account surpluses on impact. 
Figure 7. The Benchmark Consolidation

(Percent deviation from the No Policy Action Scenario, unless otherwise stated)

Fiscal Rule $=$ ER + Strict DR (10 years)

Fiscal Rule $=\mathrm{ER}+$ Flexible DR (10 years)

Fiscal Rule $=$ ER + Flexible DR (5 years)
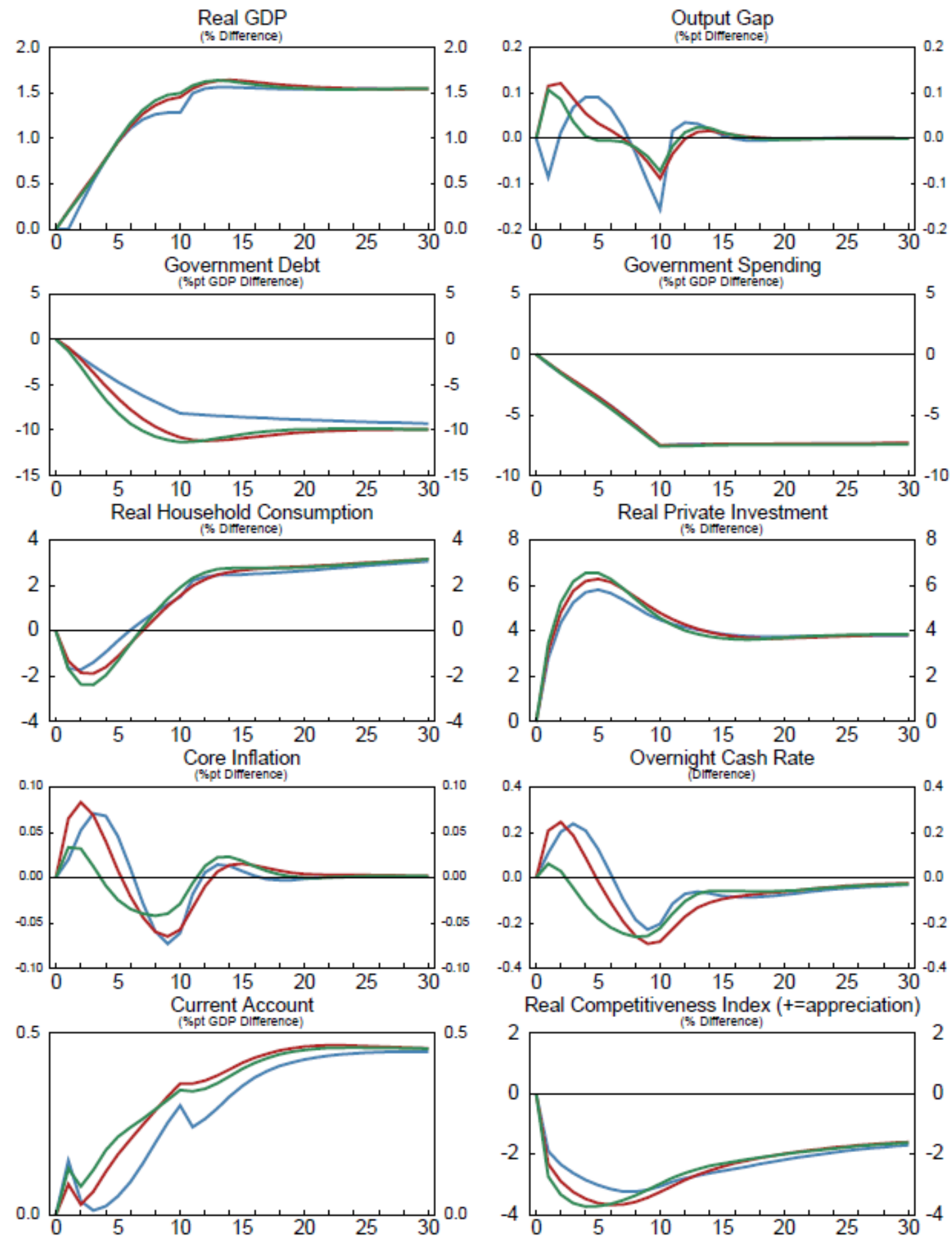

Source: IMF staff calculations. 


\section{Evaluating the Aggregated Fiscal Rules Under Illustrative Scenarios}

This subsection assesses the performance of the three candidate debt rules for operationalizing the long-term debt anchor, when shocks are hitting the economy. This is accomplished by revisiting two illustrative scenarios from the analysis above of the long-term versus mediumterm anchor - the unexpected temporary but substantial increase in aggregate demand (Box 2), and the terms-of-trade-driven boom-bust cycle (Box 3). These are then compared along with the behavior of the candidate rules under the benchmark scenario in Section V.B using the five criteria introduced (per Table 3 at the end of Section V.A).

Figure 8. The Consolidation under a Temporary but Substantial Increase in Aggregate Demand

(Percent deviation from the No Policy Action Scenario, unless otherwise stated)
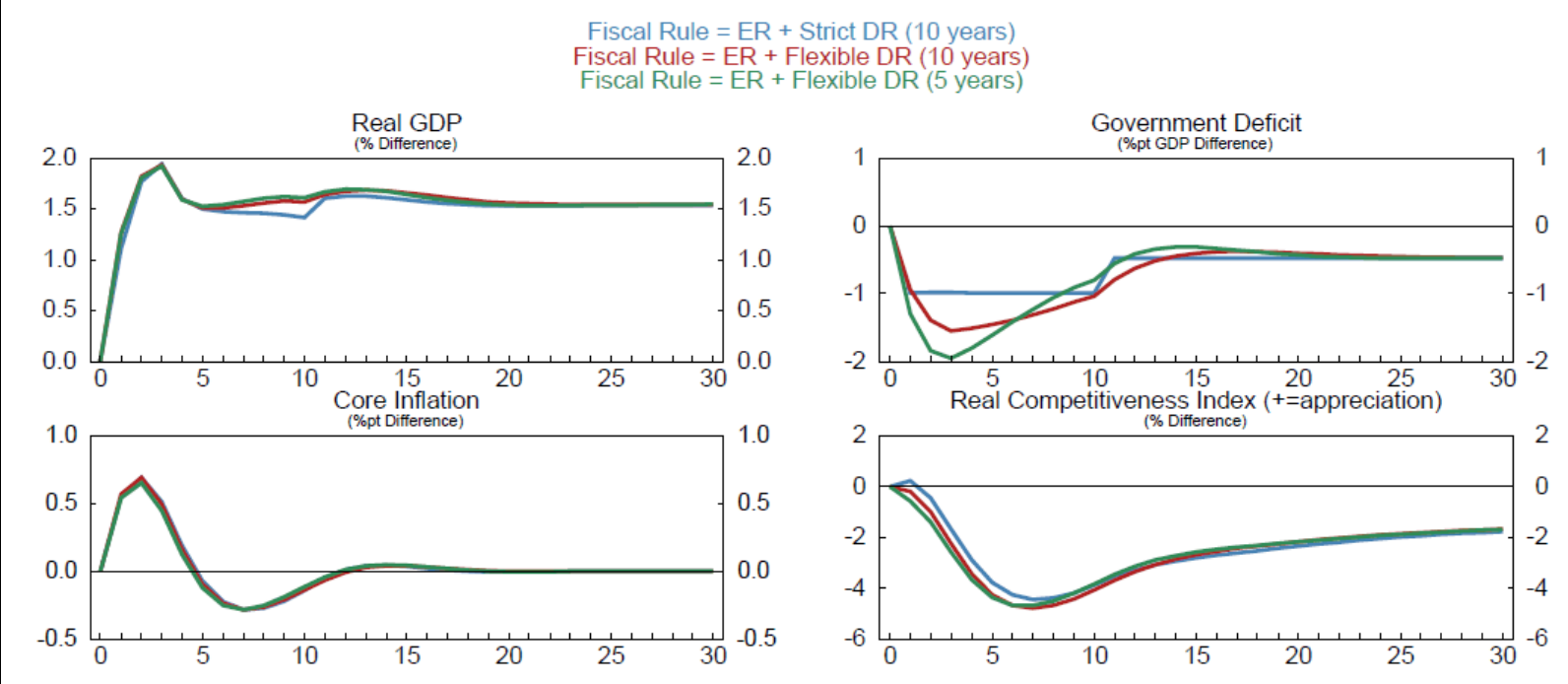

Source: IMF staff calculations.

Figure 8 considers the temporary but substantial increase in aggregate demand in the context of the benchmark consolidation. Relative to the benchmark scenario, there is more slack in the economy. There is the potential for higher revenues, and automatic social transfers are lower. Prices (including the real exchange rate) produce additional inflationary pressures, requiring a tightening in monetary policy. In terms of the aggregated fiscal rules, the primary role of the increase in aggregate demand is to modify the amount the Government needs to increase the GST to meet its debt rules. The increase in GST also dampens the effect of the shock; it is no longer just the role of monetary policy.

Figure 9 analyzes the impact of the terms-of-trade-driven boom-bust cycle on the benchmark consolidation. Real GDP is much more volatile, and this is reflected in fiscal policy, as the automatic social transfers should be more variable, causing greater interactions with the aggregated fiscal rules, but generally constrained by the ER component. Real exchange rate movements are now dominated by the commodity-driven swings, which was not the case in the benchmark consolidation, leading to an enhanced role for stability from both monetary and fiscal policy. 


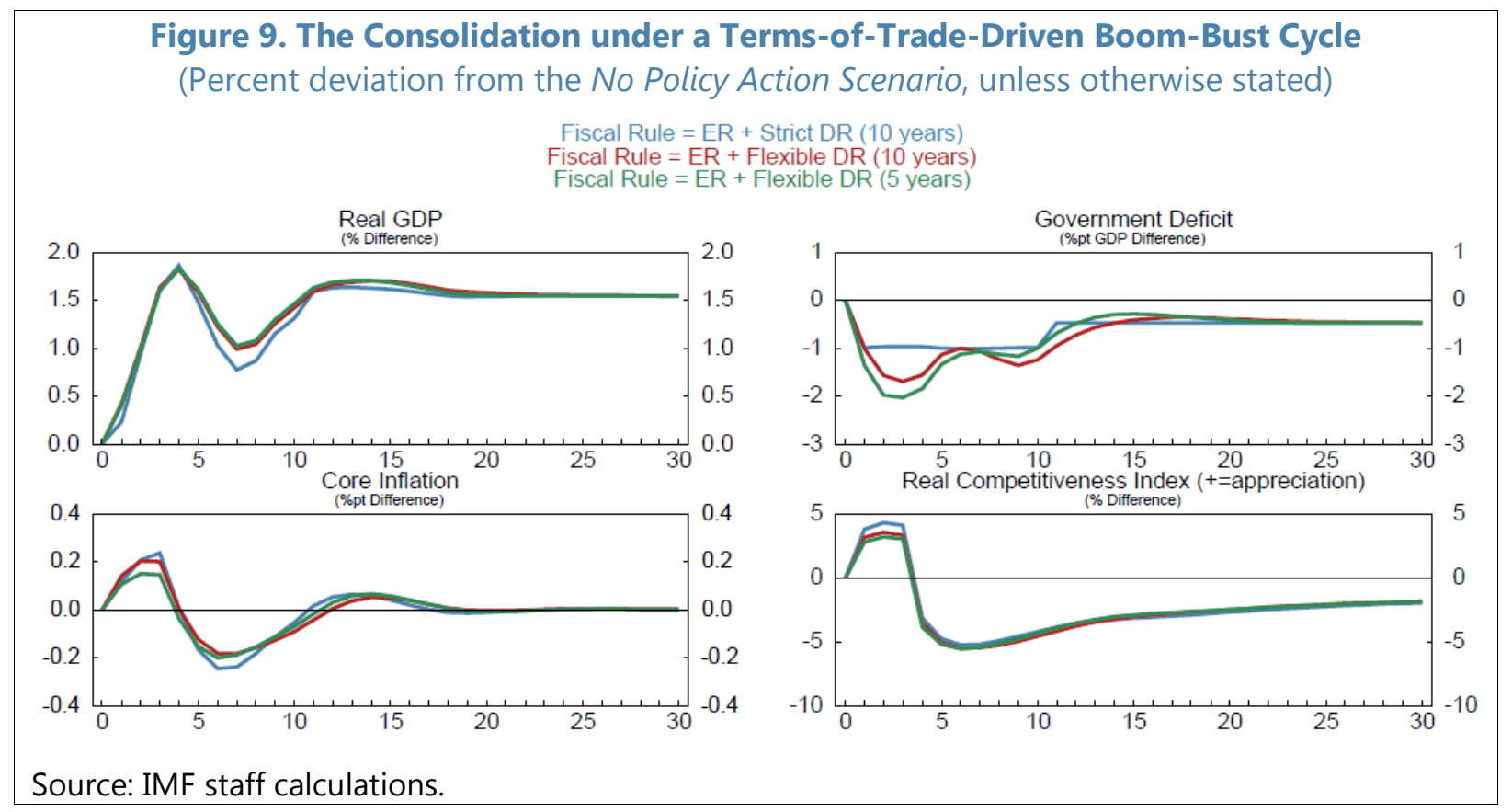

Both the ER and the DR are important for achieving the long-term debt anchor. By definition, the ER always restricts government spending. So, when the economy is expanding, it is countercyclical, all else equal, discouraging spending of additional revenues. But when there is an economic contraction, it is procyclical, all else equal, as it may offset the additional spending from automatic social transfers. On the other hand, the DR always works to reduce government debt. So, in an expansion, it is countercyclical, absorbing at least some of the fiscal gains, but it is procyclical in a contraction, as it may offset automatic social transfers, just like the ER.

Table 4 summarizes the outcomes. The pace of consolidation ([3] of the criteria in the table) is as expected, since this is a design element of the rules. At least here the rules with the ER and the flexible DR may overshoot - something that would most likely not occur in real-world implementation. The rules with the ER and the strict DR are less flexible ([1] and [2]). They also restrict faster real GDP growth under the alternative scenarios, pushing towards greater countercyclicality [4]. The opposite is true for the rules with flexible DR, becoming more procyclical. Under the benchmark consolidation, such rules are more countercyclical [4], especially under the shorter consolidation horizon of 5 years. Their flexibility also allows automatic social transfers to work, resulting in slightly more real GDP variability [5]. This can be reduced by the faster consolidation rate of 5 years. 


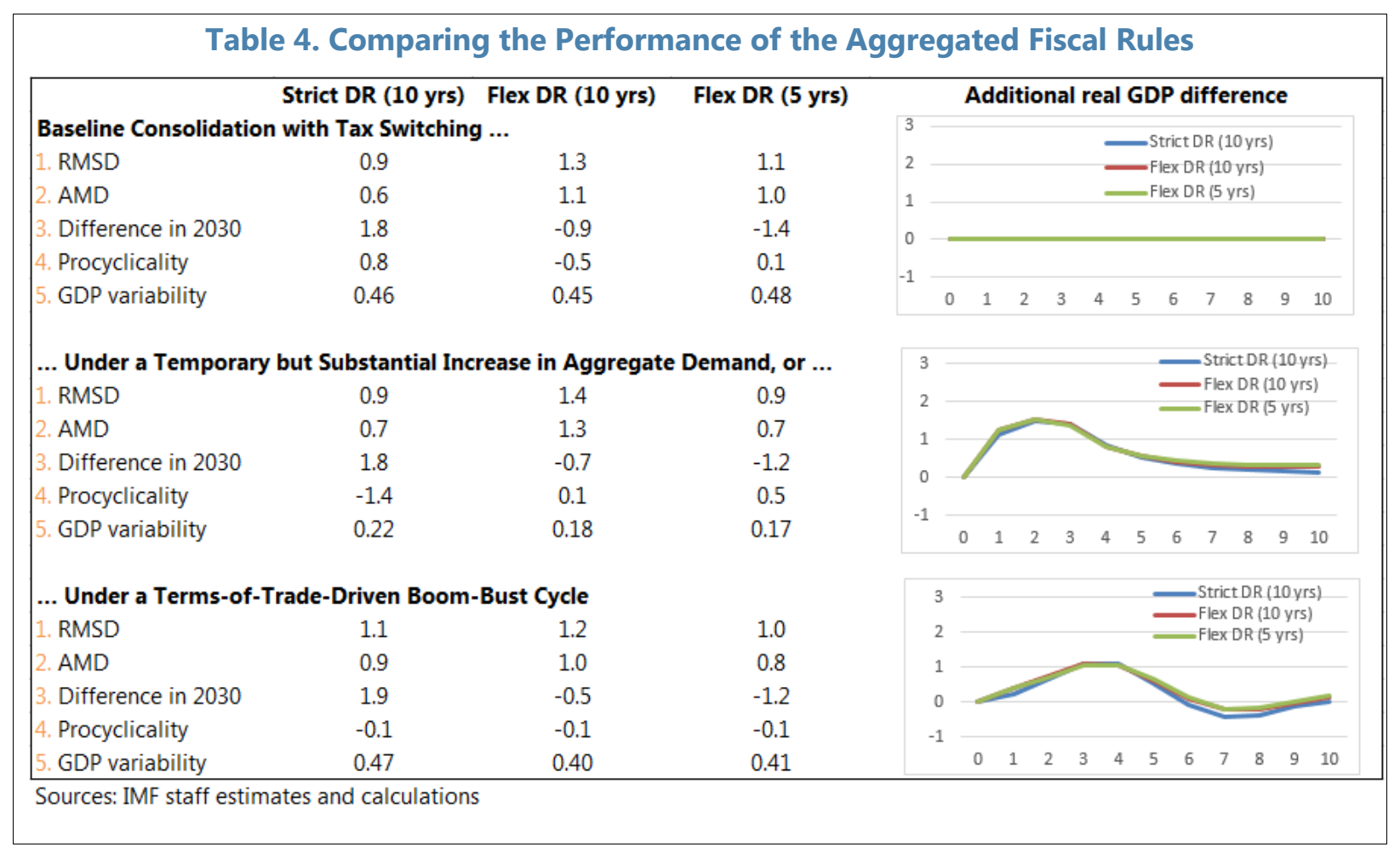

One simple way in which to evaluate which rule is the strongest for all the criteria, under all scenarios, is to compute a simple score. The simple score is a sum of a ranking from 1 to 3 (where 1 is the best performing) for each rule, under each of the five criteria, under each of the three scenarios, so that the lowest possible (best performing) score is 15 (ranking of 1, 3 times for each of 5 criteria), while the highest (worst performing) is 45 . For the three aggregated fiscal rules, the lowest score is that of the flexible DR over 10 years (score of 26), followed by the flexible DR over 5 years (score of 29), and the strict DR (score of 35). ${ }^{4}$

\section{Conclusions}

The Government has yet to achieve its budget repair strategy as part of the medium-term fiscal strategy. The net debt-to-GDP ratio continues to drift upwards, and reaching the medium-term balance anchor appears to be at a horizon whose end-point appears to continue to drift further into the future, ever since the introduction of the concept of debt repair following the global financial crisis.

This paper has revisited options for a fiscal anchor in Australia, comparing in particular the current medium-term budget balance anchor against a long-term debt anchor as an alternative. The background to this analysis is the recent upward drift in the net public debt to GDP ratio in Australia.

\footnotetext{
${ }^{4}$ In the case of the procyclicality criterion under the boom-bust scenario, where all three perform equally badly, all three rules are assigned the same ranking of 2 .
} 
A long-term anchor would avoid such upward drift in net public debt ratios. This increased certainty about the future debt path and its sustainability would be the main benefit of such an anchor. It would help households and firms in their long-term planning. But it may come at the cost of an increase in unhelpful pro-cyclical fiscal consolidation in times of economic slowdowns.

A fiscal rule based on a long-term debt anchor performs as well as, and is sometimes better than, that based on a medium-term balance anchor, when evaluated with the defined set of five criteria under three likely scenarios to hit the Australian economy. Generally, debt rules reach their anchor more quickly and have lower absolute mean deviations of the net debt-to-GDP ratio. While the analysis does not present the strongest case for a fiscal rule based on the longterm debt anchor, its case is strengthened by the fact that the analysis does not capture the increased uncertainty in economic behavior that is probably a consequence of the historical performance of the medium-term balance anchor leading to drift in the net debt-to-GDP ratio, which a debt anchor would preclude.

The operationalization of the long-term debt anchor is paired with a combination of component fiscal rules in order to maximize its efficacy. The analysis considers which combination of expenditure rules (ER) and debt rules (DR) would be better performers when trying to reach a 10 percent of GDP reduction in net debt - the 'debt norm' - under the benchmark scenario or two alternative scenarios. Considering all criteria, the flexible DR that aims to return debt to its target after 10 years has the strongest performance, when using a simple average of its rankings among the three candidate rules, across the three scenarios for the five criteria. The responsive of debt to shocks is more flexible under this rule (higher values for RMSD), which is necessary for less variable real GDP (which is observed to be the case) although there is somewhat of a sacrifice on the precision of achieving the target (the higher values for AMD).

In practice, using the GST as the adjusting fiscal instrument would require some tactical planning. The Commonwealth and State governments could reconfigure the GST such that a portion of it could accrue strictly to the Commonwealth government, which the Commonwealth could then use as a policy instrument. In that case, for example, the Government could propose a schedule of implementation for increasing the GST in its tax switching. In addition, they could announce a schedule of tax credits that increase as needed later. Another approach would be to announce tax credits even in the short term, and offset the weakening effects on revenues by broadening the tax base now. 


\section{REFERENCES}

Andrle, M., P. Blagrave, P. Espaillat, K. Honjo, B. Hunt, M. Kortelainen, R. Lalonde, D. Laxton, Mavroeidi, D. Muir, S. Mursula, and S. Snudden, 2015, "The Flexible System of Global Models_FSGM," International Monetary Fund, IMF Working Paper 15/64.

Baunsgaard, T., M. Villafuerte, M. Poplawski-Ribeiro, and C. Richmond, 2012, "Fiscal Frameworks for Resource Rich Developing Countries,” International Monetary Fund, IMF Staff Discussion Note 12/04.

Bernanke, B., M. Gertler and S. Gilchrist, 1999, "The Financial Accelerator in a Quantitative Business Cycle Framework," in J. Taylor and M. Woodford, eds., Handbook of Macroeconomics, Volume 1c, Amsterdam: Elsevier.

Blanchard, O., 1985, “Debts, Deficits and Finite Horizons," Journal of Political Economy, 93 (21): 223-47.

Commonwealth of Australia, 2009a, Updated Economic and Fiscal Outlook: February 2009, Commonwealth of Australia, Canberra, February 2009. , 2009b, Budget 2009-10: Budget Strategy and Outlook Budget Paper No. 1, 2009-10,

Commonwealth of Australia, Canberra, May 2009. , 2014a, Charter of Budget Honesty Act 1998, Office of Parliamentary Counsel, Canberra, July 2014. ,2014b, Mid-Year Economic and Fiscal Outlook 2014-15, Commonwealth of Australia, Canberra, December 2014. , 2015, 2015 Intergenerational Report: Australia in 2055, Treasurer of the Commonwealth of Australia, Canberra, March 2015. , 2016, "Treasury Analysis of Tax Mix Switch", Treasury of the Commonwealth of

Australia, Canberra, February 12, 2016, available at "Release of Tax Modelling", Media Release 005-2016 at http://sjm.ministers.treasury.gov.au/media-release/005-2016/. , 2017, Budget 2017-18: Budget Strategy and Outlook Budget Paper No. 1, 2017-18, Commonwealth of Australia, Canberra, May 2017.

Girouard, N. and C. André, 2005, "Measuring Cyclically-adjusted Budget Balances for OECD Countries," Organization for Economic Cooperation and Development, OECD Economics Department Working Paper No. 434.

IMF, 2009, "Fiscal Rules_-Anchoring Expectations for Sustainable Public Finances," IMF Staff Paper, December, 2009.

IMF, 2017, World Economic Outlook, October 2017, Washington, D.C.: International Monetary Fund.

Kinda, T., 2015, “Anchoring Sustainable Fiscal Policy: A New Fiscal Rule in Canada,” in Canada: Selected Issues, International Monetary Fund, IMF Country Report No. 15/23. 
Pitt, A., 2015, "Options for Tax Policy and Federal Fiscal Relations Reform," in Australia: Selected Issues, International Monetary Fund, IMF Country Report No. 15/275.

Rees, D., P. Smith, and J. Hall, 2015, “A Multi-Sector Model of the Australian Economy”, Reserve Bank of Australia, Reserve Bank of Australia Research Discussion Paper 201507.

Weil, P., 1987, “Permanent Budget Deficits and Inflation,” Journal of Monetary Economics 20 (2): 393-410.

Yaari, M., 1965, “Uncertain Lifetime, Life Insurance, and the Theory of the Consumer," Review of Economic Studies 32 (2): 137-50. 


\section{Appendix I: Overview of the Theoretical Structure of G20MOD}

G20MOD is an annual, multi-region, general equilibrium model of the global economy combining both micro-founded and reduced-form formulations of various economic sectors. Structurally, each country/regional block is close to identical, but with potentially different key steady-state ratios and behavioral parameters. First, the demand side of the economy is discussed, emphasizing the inclusion of an overlapping generations model for households and firms; second, the supply side and prices; and, third, the commodity sector and its role as a global stabilizer. This is followed by a brief overview of the financial features and monetary policy, concluding with a short description of the fiscal block. The interested reader is referred to Andrle and others (2015) for a more complete description of the model and its properties.

The consumption block uses a discrete-time representation of an OLG model as in Blanchard (1985), Weil (1989) and Yaari (1965). It is based on a constant-elasticity-of-substitution utility function, dependent only on household consumption. Using OLG households rather than infinitely-lived households results in important non-Ricardian properties whereby the path for government debt has significant economic implications. In the OLG framework, households treat government bonds as wealth since there is a chance that the associated tax liabilities will fall due beyond their expected lifetimes. The OLG formulation results in the endogenous determination of national savings given the level of government debt. The global real interest rate adjusts to equilibrate the global supply of and demand for savings. The use of an OLG framework necessitates the tracking of all the stocks and flows associated with wealth - human wealth (based on labor income) and financial wealth (based on government debt, the private business capital stock, and net foreign assets). It should be noted that financial markets are incomplete, so international financial flows are tracked as net positions (net foreign assets or net foreign liabilities) and denominated in U.S. dollars.

Consumption dynamics are driven not only by OLG households, but also by liquidityconstrained (LIQ) households. LIQ households do not have access to financial markets, do not save, and thus consume all their income each period. This feature amplifies the non-Ricardian properties of the basic OLG framework, particularly in the face of temporary fiscal shocks.

Private investment uses an updated version of the Tobin's Q model, with quadratic real adjustment costs. It is negatively correlated with real interest rates. Investment cumulates to the private capital stock, which is chosen by firms to maximize their profits. The capital-to-GDP ratio is inversely related to the cost of capital, which is a function of depreciation, the real corporate interest rate, the company income tax rate, and relative prices. The corporate interest rate is a mix of the 1-year and 10-year interest rates, with a risk premium negatively correlated with the output gap, to capture a financial accelerator effect as in Bernanke and others (1999).

Government absorption consists of spending on consumption good and infrastructure investment. Both are exogenous choices determined by the government. Government consumption spending only affects the level of aggregate demand. Government investment, in addition to affecting aggregate demand directly, also cumulates into a public capital stock, 
which can be thought of as public infrastructure (roads, buildings, etc.). A permanent increase in the public capital stock permanently raises the economy-wide level of productivity.

Net exports react to its long-term determinants, the real competitiveness index (RCI), adjusting to achieve the current account balance. In turn, the current account balance is required to support the desired net foreign asset position. Exports and imports, individually, are modeled as reduced-form equations. Exports increase with foreign activity, and are also an increasing function of the depreciation in the RCI. Imports increase with domestic activity, and are an increasing function of the appreciation of the real effective exchange rate (REER). The RCI differs from the REER in that it is export-weighted and accounts for third-country competition effects. In the analysis, when real exchange rate movements are mentioned, they apply equally to the RCI and the REER at least qualitatively, if not quantitatively.

The model does not track all the bilateral trade flows among countries. This keeps the dimensionality of the model small enough to allow it to have a large number of individual country blocks. The model has been developed to have exchange rate and export volume properties that are similar to the IMF's multiple-good, structural models. This is accomplished by having time-varying trade shares that are a function of the relative level of tradable and nontradable productivity within each country. Consequently, the model is able reproduce the currency appreciation that results when a country's tradable sector productivity growth exceeds that in the nontradable sector (the Balassa-Samuelson effect). Further, even though only the aggregate levels of exports and imports are tracked in each country, there are mechanisms in place that ensure global exports and imports sum to zero.

The current account and implied net-foreign-asset positions are intimately linked to the saving decision of households. The model can be used to study both creditor and debtor nations as nonzero current accounts can be a feature of the well-defined steady-state in the OLG framework.

Aggregate supply is captured by potential output. It is based on Cobb-Douglas production technology with trend total factor productivity, the steady-state labor force, the non-accelerating inflation rate of unemployment (NAIRU), and the actual capital stock. This allows for the computation of the output gap, allowing for the tracking of excess demand and excess supply, and is a key driver for prices in the economy.

There is an endogenous labor sector. Steady-state population growth is taken as exogenous, although there are cyclical variations in both the participation rate and the unemployment rate. The behavior of the participation rate is based on properties of labor supply observed in other IMF structural models, the Global Integrated Monetary and Fiscal model (GIMF) and the Global Economy Model (GEM), with both a substitution effect based on the real wage, and an income effect based on the total level of wealth in the economy. The unemployment rate varies relative to the NAIRU in the short term according to an Okun's law relationship based on the output gap.

The core price is the consumer price index excluding food and energy, CPIX, determined by an inflation Phillips curve. CPIX inflation is sticky and reflects the expected paths of exchange rates and the economic cycle, as captured by the output gap. In addition, although the direct effects of movements in food and energy prices are excluded, there is a possibility that persistent 
changes in oil prices can leak into core inflation. The degree of forward looking behavior in inflation is country specific.

Relative prices mimic the structure of the national accounts. They are usually some weighted average of a domestic consumer price and an import price. Export prices account for third country effects in its foreign component, and import prices are an import-weighted average of all other countries' export prices

In addition, there is a Phillips curve for nominal wage growth. Wage inflation exhibits stickiness and allows the real wage to return to its equilibrium only gradually depending on the expected evolution of overall economic activity and the deviation of labor supply from labor demand in the short term.

There are three commodities - oil, food and metals. Australia is an oil importer in this context, but a notable exporter of metals. The demand for commodities is driven by global demand and is relatively price inelastic in the short term due to limited substitutability of the commodity classes considered. The supply of commodities is also price inelastic in the short term. Countries trade in commodities, and households consume food and oil explicitly, allowing for the distinction between headline and core CPI inflation.

Commodities can function as a moderator of business cycle fluctuations in the model. In times of global excess aggregate demand, the upward pressure on commodities prices from sluggish adjustment in commodity supply relative to demand puts some downward pressure on global aggregate demand. Similarly, if there is global excess supply, falling commodities prices softens the effect of deterioration. However, shocks originating in the commodities sectors can be highly disruptive to global macroeconomic activity. Also, when countries' or regions' own business cycle is out of sync with the global business cycle, commodity prices act to amplify rather than dampen fluctuations in activity.

In the short term, the nominal side of the economy is linked to the real side through monetary policy. The behavior of monetary authorities is represented by an interest rate reaction function based on a 1-year interest rate, referred to as the overnight cash rate in the case of Australia. The standard form is an inflation-forecast-based rule operating under a flexible exchange rate, as is the case for Australia. Monetary policy can play a key role in fiscal matters, either by working at cross-purposes when the inflation target is being strictly pursued in a time of deliberate fiscal stimulus, or by working in tandem by allowing monetary accommodation at the appropriate times. Under constrained monetary policy space and rising probability of hitting the effective lower bound on interest rates, overly ambitious fiscal consolidation can exacerbate the cost to the economy.

Long-term interest rates affect households' and firms' decisions. The model features a 10-year interest rate, based on the expectations theory of the term structure, plus a term premium. The interest rates on consumption, investment, government debt and net foreign assets are weighted averages of the 1-year and 10-year interest rates, reflecting their differing term structures, and allowing for a meaningful role for the term premium. 
Fiscal policy is driven by a sufficiently detailed government sector that can reproduce simplified fiscal accounts for each country. Eight policy instruments are featured. On the spending side, in addition to government consumption and spending on infrastructure spending, there are general lumpsum transfers to all households (such as pensions, aged care provisions, unemployment insurance) and lumpsum transfers targeted to LIQ households (such as welfare, certain pensions). On the revenues side, there are taxes on consumption (the goods and services tax, GST), personal income (PIT, on both wage and dividend income) and company income (CIT), as well as taxes and royalties from the mining and production of metals. For Australia, the government is an amalgam of the Commonwealth and State governments. However, many of the issues in this paper focus on the Commonwealth accounts and balances.

Relative to other versions of G20MOD, there is more detail related to the taxation of firm (or 'company') income, which applies specifically to Australia. Firms pay CIT and issue dividends. Households notionally pay their marginal tax rate on dividend income as part of their payment of PIT (along with taxes on their wage income). In Australia, households are rebated the tax amount already paid by firms as CIT - the dividends are "franked." This means that if the CIT rate is lowered, the amount of franked dividends that OLG households receive will be reduced, and the dividend income tax portion of their PIT liability will be higher. Therefore, if there is a tax switch from CIT to PIT, not only will the PIT liability on households increase, the burden of the increase will fall on OLG households, as they are solely responsible for the dividend income portion. Only the wage income portion of the PIT increase will be shared with LIQ households.

The budget constraint in the model is met by the choice of a long-term deficit target, relative to GDP. Specifically, the deficit is expenditures and interest payments, less revenues. One instrument, which is general lumpsum transfers by default, is constantly adjusted to make sure that the budget constraint always holds. The long-term government debt target, relative to GDP, can be derived from the government deficit target, based on the nominal growth rate of the economy:

$$
b^{t a r}=\frac{(1+\pi)(1+g)}{(1+\pi)(1+g)-1} g d e f^{t a r}
$$

where $\pi$ is inflation, $g$ is the steady-state growth rate, $b^{\text {tar }}$ is the long-term debt target, and $g_{d e f^{t a r}}$ is the long-term deficit target. The explicit deficit target therefore pins down the longterm government debt, a fundamental decision variable for firms and households worldwide. The level of government debt affects the global interest rate (the price used to equilibrate global saving with global investment), and the real exchange rate (a country's relative price for its contributions and use of the global saving-investment pool). The operational implementation of the deficit target is complemented with the use of fiscal rules, which are explained more fully in the body of the paper. 